\title{
Global pandemics interconnected - obesity, impaired metabolic health and COVID-19
}

Norbert Stefan (1) ${ }^{1,2,3 凶}$, Andreas L. Birkenfeld ${ }^{1,2,3,4}$ and Matthias B. Schulze $\mathbb{1}^{3,5,6}$

Abstract $\mid$ Obesity and impaired metabolic health are established risk factors for the non-communicable diseases (NCDs) type 2 diabetes mellitus, cardiovascular disease, neurodegenerative diseases, cancer and nonalcoholic fatty liver disease, otherwise known as metabolic associated fatty liver disease (MAFLD). With the worldwide spread of severe acute respiratory syndrome coronavirus 2 (SARS-CoV-2), obesity and impaired metabolic health also emerged as important determinants of severe coronavirus disease 2019 (COVID-19). Furthermore, novel findings indicate that specifically visceral obesity and characteristics of impaired metabolic health such as hyperglycaemia, hypertension and subclinical inflammation are associated with a high risk of severe COVID-19. In this Review, we highlight how obesity and impaired metabolic health increase complications and mortality in COVID-19. We also summarize the consequences of SARS-CoV-2 infection for organ function and risk of NCDs. In addition, we discuss data indicating that the COVID-19 pandemic could have serious consequences for the obesity epidemic. As obesity and impaired metabolic health are both accelerators and consequences of severe COVID-19, and might adversely influence the efficacy of COVID-19 vaccines, we propose strategies for the prevention and treatment of obesity and impaired metabolic health on a clinical and population level, particularly while the COVID-19 pandemic is present.

As of 20 December 2020, more than 75 million people have been infected with severe acute respiratory syndrome coronavirus 2 (SARS-CoV-2) and more than 1.6 million deaths worldwide were attributed to coronavirus disease 2019 (COVID-19) ${ }^{1}$. On the basis of the infection to fatality ratio, the mortality of individuals with COVID-19 is $\sim 2 \%{ }^{1}$. However, this widely used ratio is not the ideal measure of overall mortality as it only relates to confirmed infections and confirmed deaths. The infection to fatality ratio might be inaccurate owing to a delay of several weeks between symptom onset and death, and because surveillance-based case reports underestimate the total number of patients infected with SARS-CoV-2, as testing focuses on individuals with symptoms. In most instances, the symptomatic infection to fatality ratio and infection to fatality ratio show largely different numbers ${ }^{2}$.

After infection with SARS-CoV-2, individuals can remain asymptomatic. By contrast, in symptomatic individuals the disease course can follow various stages: for example, mild symptoms in the initial 2 weeks after infection that can then progress to more complicated disease, defined by the severity of clinical symptoms and the potential for recovery. Patients who require hospital treatment have a considerably increased risk of death due to COVID-19. For example, the mortality of hospitalized patients with COVID-19 ranges from 10\% to $26 \%$ in the USA, the UK, Italy and Germany ${ }^{3-7}$. Mortality increases further to $22-48 \%$ in patients with COVID-19 who were admitted to an intensive care unit (ICU) $)^{3-7}$. Therefore, for risk stratification purposes it is crucial to understand the parameters that predispose patients with SARS-CoV-2 infection to a severe course of COVID-19.

Older age and male sex are well established as risk factors for severe COVID-19. The median age of hospitalized patients varies between 47 and 73 years, and in most cohort studies the percentage of men was $\sim 60 \%{ }^{8}$. Furthermore, although only $\sim 25 \%$ of all patients infected with SARS-CoV-2 have comorbidities, $60-90 \%$ of hospitalized patients with COVID-19 have comorbidities ${ }^{8}$. The first studies reporting characteristics of hospitalized patients with COVID-19 showed that the most common comorbidities were hypertension, diabetes mellitus, cardiovascular disease (CVD), chronic pulmonary disease, chronic kidney disease, cancer and chronic liver disease $^{8,9}$. Only since mid-April 2020 has obesity been recognized as an important comorbidity ${ }^{10,11}$. In addition, hyperglycaemia in the non-diabetic range (that is, 


\section{Key points \\ - Obesity, particularly severe obesity, is a strong and independent determinant of severe coronavirus disease 2019 (COVID-19); novel studies also suggest that visceral obesity increases the risk of complications. \\ - Although diabetes mellitus is an established risk factor for severe COVID-19, evidence is increasing that hyperglycaemia in the non-diabetic and diabetic range also strongly predicts severe COVID-19. \\ - Severe acute respiratory syndrome coronavirus 2 (SARS-CoV-2) targets organs and tissues that are relevant for cardiometabolic health; SARS-CoV-2-induced organ or tissue dysfunction could result in an increased incidence of cardiometabolic diseases. \\ - Targeted interventions for metabolic pathologies could improve management of COVID-19; the SARS-CoV-2 vaccination response should be carefully evaluated in patients with obesity and/or diabetes mellitus because of a potentially reduced response. \\ - Programmes resulting in weight loss and the improvement of metabolic health in people with metabolically unhealthy obesity should be implemented at the patient level and in the public health sector. \\ - Research to understand how diet and nutritional status modify the immune response could help explain some of the variability in COVID-19 morbidity and mortality and improve patient outcomes.}

people with prediabetes, impaired glucose tolerance or isolated fasting glycaemia) is now recognized as an important determinant of severe COVID-19 (REFS ${ }^{12-14}$ ). Furthermore, in patients with type 2 diabetes mellitus (T2DM) and COVID-19, good glucose control near the target range was associated with decreased mortality ${ }^{15}$. These data support the hypothesis that we proposed in April 2020 (REF. ${ }^{16}$ ), that obesity and impaired metabolic health might strongly, and independently of other comorbidities, associate with increased risk of severe COVID-19. We consider this aspect very important, as both obesity and impaired metabolic health are modifiable risk factors that can often be effectively treated by lifestyle intervention.

In this Review, we build upon this hypothesis. First, we summarize the data of the largest studies investigating the strength of the independent relationships of obesity, visceral obesity and impaired metabolic health with severe COVID-19. Second, we discuss the consequences of SARS-CoV-2 infection for organ function in infected patients and their risk of future cardiometabolic diseases; severely ill patients with COVID-19 can die of organ failure that is related to their underlying illness, such as CVD, diabetes mellitus, kidney disease, liver disease ${ }^{17}$ or obesity-related complications ${ }^{16}$. We consider this issue important, particularly because impaired organ function can persist even after patients have fully recovered from the viral infection. Third, we propose strategies to

\footnotetext{
Author addresses

${ }^{1}$ Institute of Diabetes Research and Metabolic Diseases (IDM), the Helmholtz Center, Munich, Germany.

${ }^{2}$ Department of Internal Medicine IV, Division of Endocrinology, Diabetology and Nephrology, University Hospital of Tübingen, Tübingen, Germany. ${ }^{3}$ German Center for Diabetes Research (DZD), Neuherberg, Germany. ${ }^{4}$ Department of Diabetes, School of Life Course Science, King's College London, London, UK.

${ }^{5}$ Department of Molecular Epidemiology, German Institute of Human Nutrition Potsdam-Rehbruecke, Nuthetal, Germany.

${ }^{6}$ Institute of Nutritional Science, University of Potsdam, Potsdam, Germany.
}

prevent and treat obesity and impaired metabolic health on a clinical and population level, particularly while the COVID-19 pandemic is present.

\section{Severity of COVID-19}

Obesity and severity of COVID-19. Based on data from the WHO, last updated in 2018, globally, $13 \%$ of adults aged 18 years and older had obesity in $2016\left(\right.$ REF. $\left.^{18}\right)$. The highest prevalence of obesity ( $>35 \%)$ was observed in the USA and in Saudi Arabia and a high prevalence of obesity (>20\%) was also observed in Turkey, Egypt, Libya, Iran, Iraq, South Africa, Canada, Mexico, Australia and in most of the countries in South America and Europe. In addition, data from the WHO, last updated on 29 November 2020, show that in these countries with high obesity prevalence, a high cumulative number of confirmed COVID-19-related deaths per million people is being observed ${ }^{19}$. The question is whether there is a relationship between obesity and severe COVID-19. Furthermore, the risk of severe COVID-19 is high in older adults (aged $>65$ years), and obesity is thought to shift this increased risk of severe COVID-19 into younger age groups ${ }^{20}$. However, because obesity ${ }^{21}$ and, more importantly, metabolically unhealthy obesity ${ }^{22}$ are associated with an increased risk of cardiometabolic diseases, which themselves correlate with severe COVID-19, it is unclear whether obesity is an independent determinant of COVID-19 severity (TABLE 1).

The first studies investigating the relationship between obesity and COVID-19 had fairly small sample sizes. For example, a study from a university hospital in Lille, France, reported data from 124 patients with COVID-19 admitted to the ICU, and saw that the odds ratio (OR) for invasive mechanical ventilation requirement in patients with a BMI of $\geq 35 \mathrm{~kg} / \mathrm{m}^{2}$ was $7.36(95 \%$ CI 1.63 $33.14)$, compared with patients with a BMI of $<25 \mathrm{~kg} / \mathrm{m}^{2}$ $\left(\right.$ REF. $\left.^{10}\right)$. This association was independent of age, sex and comorbidities (such as diabetes mellitus, hypertension or dyslipidaemia). Furthermore, a study from Shenzhen, China, among 383 hospitalized patients with COVID19 found that overweight (BMI $24.0-27.9 \mathrm{~kg} / \mathrm{m}^{2}$ ) and obesity (BMI $\geq 28 \mathrm{~kg} / \mathrm{m}^{2}$ ) were associated with a multivariate adjusted OR of 1.84 (95\% CI 0.99-3.43) and 3.40 (95\% CI 1.40-2.86), respectively, for developing severe pneumonia, compared with patients of normal weight (BMI $\left.18.5-23.9 \mathrm{~kg} / \mathrm{m}^{2}\right)\left(\mathrm{REF}^{23}\right)$. In addition, a study examined 75 patients with obesity and COVID-19 in three hospitals in China, who were matched 1:1 by age and sex to 75 patients with COVID-19 but not obesity. In this study, obesity was associated with an approximately threefold increased risk of having severe COVID-19 (OR 3.00; 95\% CI 1.22-7.38), after adjustment for age, sex, smoking status, hypertension, diabetes mellitus and dyslipidaemia ${ }^{24}$.

Several larger studies have subsequently been published, investigating more than 1,000 patients each. According to two US studies, patients with SARS-CoV-2 infection were at increased risk of hospital admission if they had obesity ${ }^{11,25}$. Furthermore, a BMI of $\geq 40 \mathrm{~kg} / \mathrm{m}^{2}$ was associated with a greater than twofold increase in risk of hospitalization compared with patients of normal weight (OR 2.45; 95\% CI 1.78-3.36), independent 
Table 1 | Summary table of the independent association of obesity with COVID-19 severity

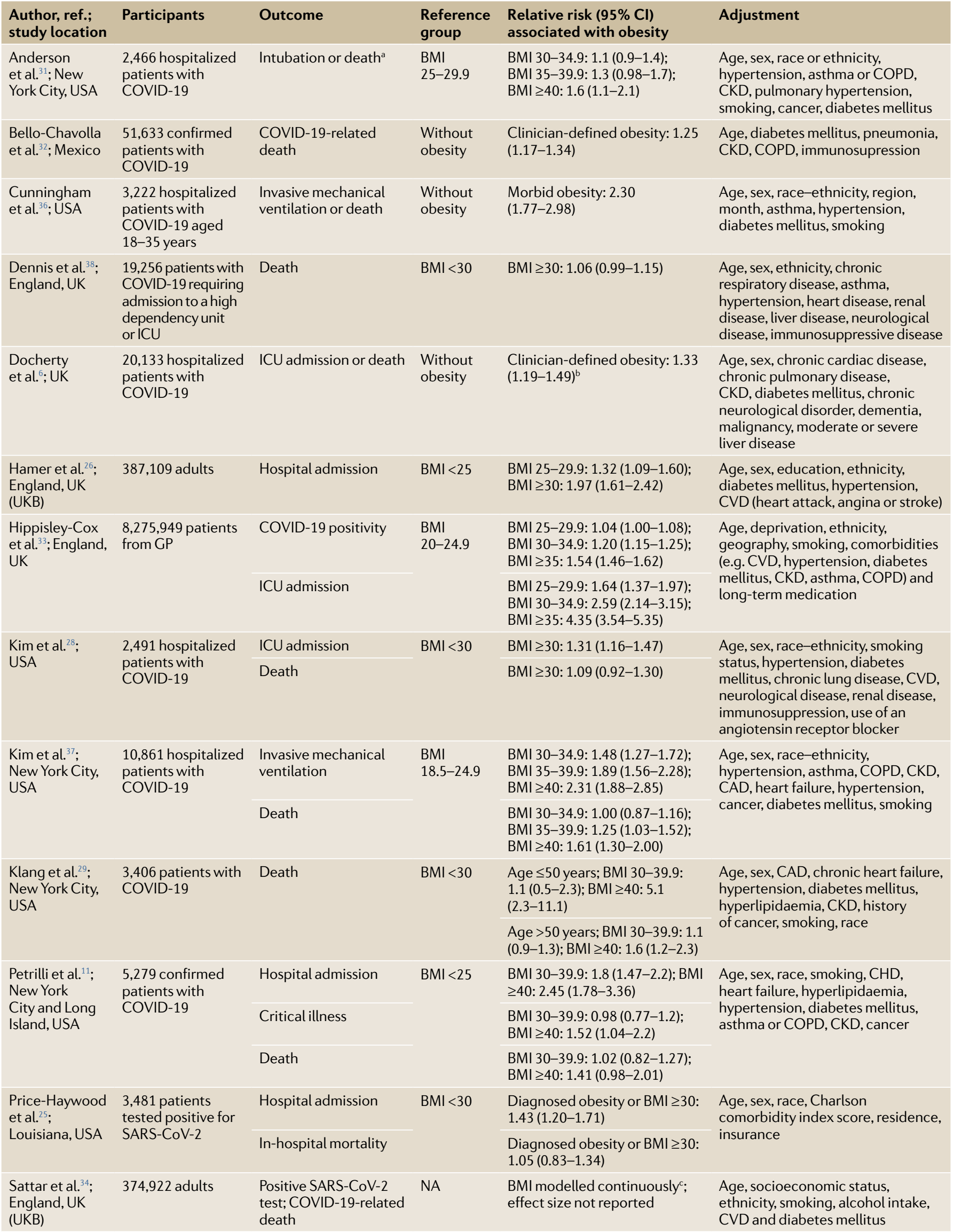


Table 1 (cont.) | Summary table of the independent association of obesity with COVID-19 severity

\begin{tabular}{|c|c|c|c|c|c|}
\hline $\begin{array}{l}\text { Author, ref.; } \\
\text { study location }\end{array}$ & Participants & Outcome & $\begin{array}{l}\text { Reference } \\
\text { group }\end{array}$ & $\begin{array}{l}\text { Relative risk }(95 \% \mathrm{Cl}) \\
\text { associated with obesity }\end{array}$ & Adjustment \\
\hline $\begin{array}{l}\text { Simonnet } \\
\text { et al. }{ }^{10} \text {; Lille, } \\
\text { France }\end{array}$ & $\begin{array}{l}124 \text { patients } \\
\text { admitted in } \\
\text { intensive care }\end{array}$ & $\begin{array}{l}\text { Invasive mechanical } \\
\text { ventilation }\end{array}$ & $\mathrm{BMI}<25$ & $\begin{array}{l}\text { BMI 25-29.9: } 1.69 \text { (0.52-5.48); } \\
\text { BMI 30-34.9: 3.45 (0.83-14.31); } \\
\text { BMI 35: 7.36 (1.63-33.14) }\end{array}$ & $\begin{array}{l}\text { Age, sex, diabetes mellitus, } \\
\text { hypertension, dyslipidaemia }\end{array}$ \\
\hline $\begin{array}{l}\text { Soares et al. }{ }^{27} \text {; } \\
\text { Espirito Santo } \\
\text { state, Brazil }\end{array}$ & $\begin{array}{l}10,713 \text { patients } \\
\text { diagnosed with } \\
\text { COVID-19 }\end{array}$ & Hospital admission & $\begin{array}{l}\text { Without } \\
\text { obesity }\end{array}$ & Obesity: $1.74(1.35-2.23)^{d}$ & $\begin{array}{l}\text { Age, sex, race, CVD, diabetes } \\
\text { mellitus, kidney disease, pulmonary } \\
\text { diseases, smoking, symptoms }\end{array}$ \\
\hline $\begin{array}{l}\text { Williamson } \\
\text { et al. }{ }^{30} \text {; } \\
\text { England, UK }\end{array}$ & $\begin{array}{l}17,278,392 \text { adult } \\
\text { patients registered } \\
\text { with GP EHR }\end{array}$ & $\begin{array}{l}\text { COVID-19-related } \\
\text { death }\end{array}$ & $\mathrm{BMI}<30$ & 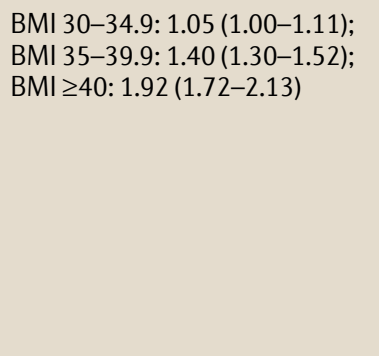 & $\begin{array}{l}\text { Age, sex, smoking, ethnicity, IMD, } \\
\text { blood pressure, respiratory disease, } \\
\text { asthma, heart disease, diabetes } \\
\text { mellitus, cancer, haematological } \\
\text { malignancy, reduced kidney } \\
\text { function, liver disease, stroke or } \\
\text { dementia, other neurological } \\
\text { disease, organ transplant, asplenia, } \\
\text { rheumatoid arthritis or lupus or } \\
\text { psoriasis, other immunosuppressive } \\
\text { conditions }\end{array}$ \\
\hline \multicolumn{6}{|c|}{ 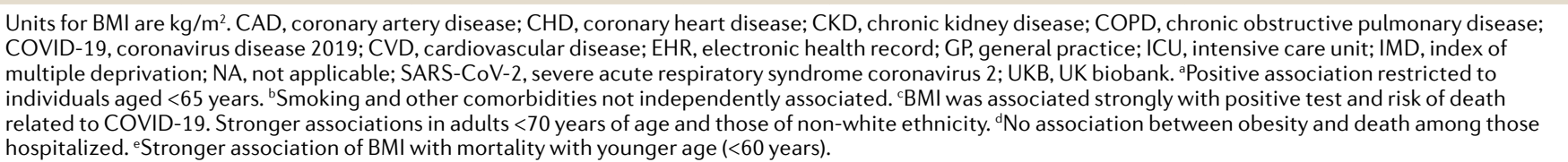 } \\
\hline
\end{tabular}

of age, sex, ethnicity and a variety of comorbidities ${ }^{11}$. Similarly, in a study carried out in Louisiana, USA, patients with COVID-19 and obesity or with a recent (previous 12 months) BMI measurement $\geq 30 \mathrm{~kg} / \mathrm{m}^{2}$ had an adjusted OR of 1.43 for hospital admission, compared with patients who did not have obesity ${ }^{25}$. Furthermore, increased risk of hospitalization for COVID-19 in individuals with obesity, independent of other determinants, has been reported from the UK Biobank ${ }^{26}$ and a study in Brazil involving more than 10,000 patients ${ }^{27}$. Moreover, several studies support that obesity is an important factor determining the severity of COVID-19 among hospitalized patients $s^{6,11,25,28-37}$. End points in the aforementioned studies vary, and include ICU admission, intubation, mechanical ventilation and in-hospital death, as well as composite end points. Nevertheless, these studies uniformly observed increased risk of a more critical COVID-19 course among patients with obesity. For example, the multivariate adjusted OR for critical illness in patients with a BMI $\geq 40 \mathrm{~kg} / \mathrm{m}^{2} \mathrm{com}-$ pared with patients of normal weight was 1.52 (95\% CI 1.04-2.20) $\left(\right.$ REF. $\left.^{11}\right)$. Similarly, in a USA-wide study, patients with $\mathrm{BMI} \geq 30 \mathrm{~kg} / \mathrm{m}^{2}$ were at 1.31-times higher risk of ICU admission than patients without obesity ${ }^{28}$.

With regard to mortality, the relationship with obesity seems slightly less clear. Most studies could not confirm statistically significant independent associations, although point estimates of the OR suggest an increased risk of death in people with obesity ${ }^{11,25,28,38}$; however, in some studies, composite end points were investigated ${ }^{6,31,39}$. Nevertheless, studies from southern
California $^{35}$, New York City ${ }^{37}$ and the UK Biobank ${ }^{34}$ support our hypothesis that obesity is associated with increased mortality in COVID-19. This association might be stronger in younger people than in older people $e^{29,35,36}$. The largest study investigating relationships of comorbidities and mortality in patients with COVID-19 was published on behalf of the National Health Service England OpenSAFELY, a secure health analytics platform covering $40 \%$ of all patients in England. Within OpenSAFELY, primary care records of $17,278,392$ adults were anonymously linked to 10,926 COVID-19-related deaths. Patients with obesity had a higher multivariate adjusted risk of mortality compared with individuals without obesity and the highest risk of death was observed in individuals with a BMI $>40 \mathrm{~kg} / \mathrm{m}^{2}$ (fully adjusted HR 1.92; 95\% CI 1.72-2.13) (REF. ${ }^{30}$.

To better estimate how obesity compares with other established comorbidities in predicting the risk of COVID-19-associated death, we have summarized the data about age, sex, obesity, smoking, diabetes mellitus, reduced kidney function, chronic respiratory disease, chronic liver disease and stroke or dementia (FIG. 1). Increasing age was most strongly associated with mortality risk, with those aged $\geq 80$ years having a $>20$-fold increased risk compared with those aged $50-59$ years (fully adjusted HR 20.61; 95\% CI 18.72-22.70). In agreement with most of the previously published studies, male sex was also associated with an increased mortality risk (fully adjusted HR 1.59; 95\% CI 1.53-1.65) (REF. ${ }^{30}$ ). Furthermore, non-white ethnicity, deprivation and most comorbidities were associated with an increased 
risk of death ${ }^{30}$. However, the excess mortality associated with obesity is similar to or higher than that of many comorbidities, including hypertension, diabetes mellitus, asthma and other respiratory diseases or cancer ${ }^{30}$.

Visceral obesity and severity of COVID-19. In individuals with or without obesity, disproportionate adipose tissue distribution, and particularly increased visceral adipose mass ${ }^{40,41}$, strongly and independently predict an increased risk of cardiometabolic diseases. The relationships of BMI and adipose tissue distribution with COVID-19-related hospitalization in the ICU and/or invasive mechanical ventilation was investigated in 30 patients with COVID-19 from a medical centre in Berlin, Germany ${ }^{42}$. In this study, each $10 \mathrm{~cm}^{2}$ increase in visceral adipose area measured by CT was associated with an OR of 1.37 (95\% CI 1.07-1.89) for ICU treatment and an OR of 1.32 (95\% CI 1.04-1.91) for mechanical ventilation (both adjusted for age and sex).

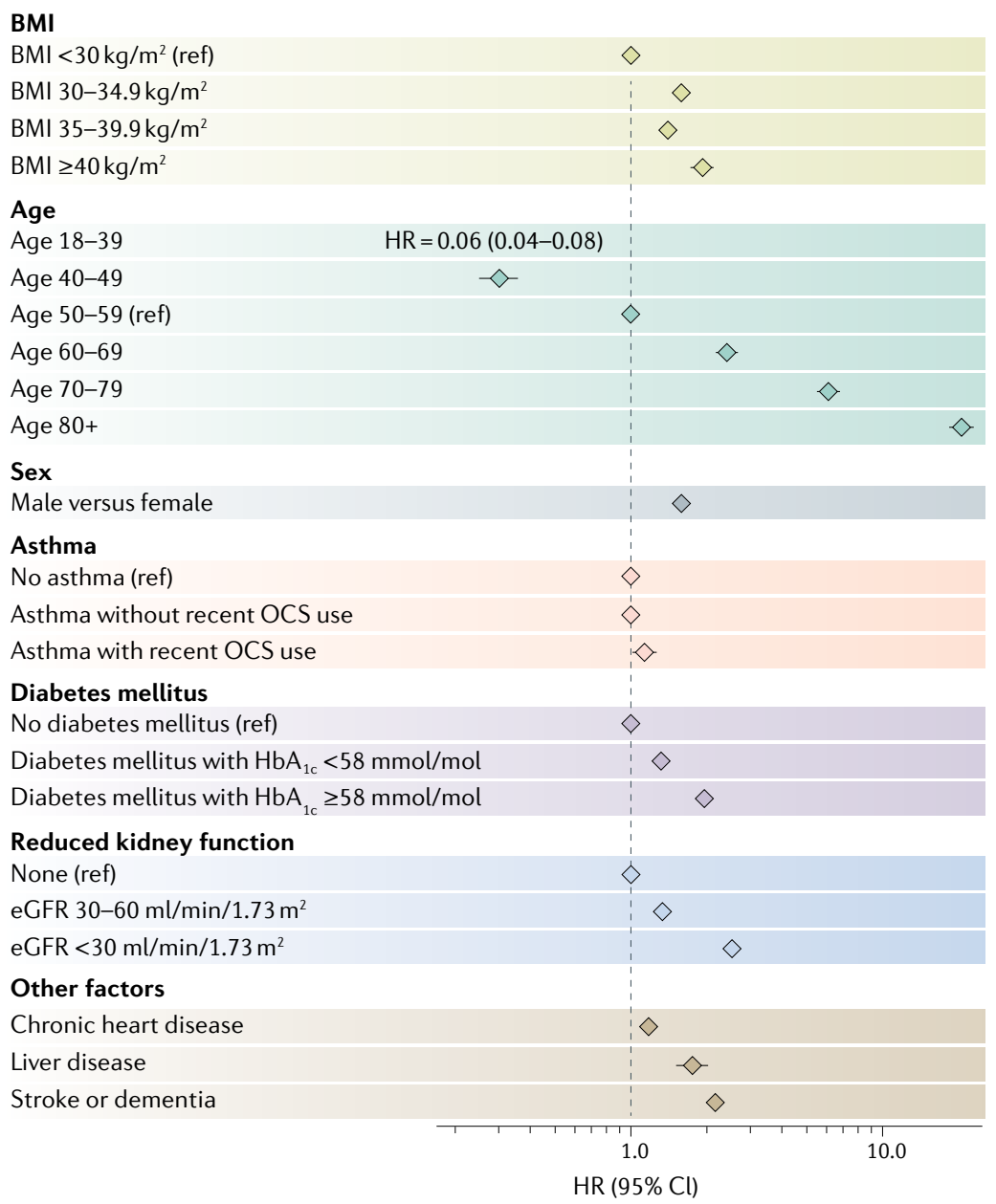

Fig. 1 Selected estimated and adjusted hazard ratios for risk factors for COVID-19 death in OpenSAFELY. The data derive from Williamson et al. ${ }^{30}$, using OpenSAFELY, a new data analytics platform created to address urgent questions relating to the epidemiology and treatment of coronavirus disease 2019 (COVID-19) in England. Error bars represent limits of the $95 \%$ confidence interval for the hazard ratio. All hazard ratios are adjusted for all other factors listed in figure 3 of the original publication by Williamson et al..$^{30}$, other than ethnicity. Total $n=17,278,392$. The different colours show different categories of risk factor. eGFR, estimated glomerular filtration rate; OCS, oral corticosteroid; Ref, reference group. Adapted from REF. ${ }^{30}$, Springer Nature Limited.
Interestingly, BMI was not associated with the severity of COVID-19 (REF. ${ }^{42}$ ). Furthermore, a study investigating 150 patients with COVID-19 from an emergency department in Rome, Italy, found that for each unit of increase in the visceral adipose tissue area, measured by chest CT, there was an OR of 2.47 (95\% CI 1.02-6.02) for the need for intensive care, independently of age, sex, diabetes mellitus, CVD, hypertension, kidney failure, inflammatory markers, malignancies, pharmacological treatment, total adipose tissue area and subcutaneous adipose tissue area ${ }^{43}$. Interestingly, in the same statistical model, total adipose tissue area was no longer an independent determinant of the need for intensive care ${ }^{43}$. In addition, using similar parameters for adjustment, a study investigating 143 patients with COVID-19 in a hospital in Wuhan, China, found that a high $(\geq 1.33$ in men and $\geq 0.71$ in women) visceral to subcutaneous adipose tissue area ratio measured by abdominal CT (OR 2.47; 95\% CI 1.05-5.98) was an independent risk factor for critical illness, compared with those with values below this threshold ${ }^{44}$. If replicated in larger studies, these findings might support the hypothesis that visceral obesity is superior to general obesity in predicting the outcome in patients with COVID-19.

Hyperglycaemia and severity of COVID-19. Hyperglycaemia is independently associated with an increased risk of cardiometabolic diseases and mortality, even when it occurs in the non-diabetic range ${ }^{45-47}$. Studies also support the relevance of hyperglycaemia for COVID-19 outcomes. For example, among 605 patients with COVID-19 in two hospitals in Wuhan, China, patients with a fasting blood glucose (FBG) level during hospital admission of $6.1-6.9 \mathrm{mmol} / \mathrm{l}$ had an adjusted OR of 2.61 (95\% CI 1.64-4.41) for 28-day in-hospital complications, compared with patients with a FBG level $<6.1 \mathrm{mmol} / 1$ (REF. ${ }^{13}$ ). Furthermore, among 461 patients with COVID-19 treated in six hospitals in Guangdong, China, FBG on admission (OR per mmol/1 1.22; 95\% CI 1.05-1.40) was independently associated with poor 30-day outcome (acute respiratory distress syndrome, multiple organ dysfunction, ICU admission, septic shock or death), even after adjustment for pre-existing diabetes mellitus. The area under the curve of FBG for predicting poor 30 -day outcome was 0.817 (95\% CI 0.765-0.868) and the optimal FBG cut-off was $\geq 6.23 \mathrm{mmol} / \mathrm{l}$, with a sensitivity of $75.6 \%$ and specificity of $77.0 \%\left(\mathrm{REF}^{48}\right)$.

In a cohort of 339 patients with COVID-19 who were consecutively hospitalized at four sites in Wenzhou, China, the presence of diabetes mellitus was associated with an approximately fourfold increased risk of severe COVID-19 illness (unadjusted OR 3.83; 95\% CI 2.06-7.13). This association remained statistically significant after adjustment for age, sex, obesity, hypertension and smoking history (adjusted OR 2.05; 95\% CI 1.01-4.19) (REF. ${ }^{49}$ ). Furthermore, in a whole-population study among all individuals registered with general practice centres in England $(n=61,414,470)$, the multivariateadjusted risk for in-hospital COVID-19-related death was 2.86 (95\% CI 2.58-3.18) for patients with type 1 diabetes mellitus (T1DM) $(n=263,830)$ and $1.80(95 \%$ CI $1.75-1.86)$ for those with T2DM $(n=2,864,670)\left(\right.$ REF. $\left.^{50}\right)$. 
Mendelian randomization analysis

A research method that provides evidence about putative causal relationships between modifiable risk factors and disease, using genetic variants.
Moreover, in this population-based cohort, increased COVID-19-related mortality was independently associated with cardiovascular and renal complications of diabetes mellitus and with glycaemic control and $\mathrm{BMI}^{51}$

In a study of 453 patients with COVID-19 admitted to Union Hospital in Wuhan, China, patients with newly diagnosed diabetes mellitus had the highest risk of ICU admission (11.7\% were admitted to ICU) and were most likely to require invasive mechanical ventilation (11.7\%), followed by patients with known diabetes mellitus (4.1\% ICU; 9.2\% mechanical ventilation) and patients with hyperglycaemia (FBG $5.6-6.9 \mathrm{mmol} / 1$ and/or $\mathrm{HbA}_{1 \mathrm{c}}$ 5.7-6.4\%: 6.2\% ICU; 4.7\% mechanical ventilation), compared with patients with normal glucose levels (1.5\% ICU; $2.3 \%$ mechanical ventilation). The multivariable-adjusted hazard ratios of mortality among COVID-19 patients with hyperglycaemia, newly diagnosed diabetes mellitus or known diabetes mellitus compared with patients with normal glucose levels were 3.29 (95\% CI 0.65-16.6), 9.42 (95\% CI 2.18-40.7) and 4.63 (95\% CI 1.02-21.0), respectively ${ }^{52}$.

Finally, the largest study addressing the relationship of blood levels of glucose at the point of hospital admission with the course of COVID-19 was an analysis that included 2,041 consecutive hospitalized patients with COVID-19 from Wuhan, China. This study showed that higher median glucose level during hospital stay or after critical diagnosis $(\geq 6.1 \mathrm{mmol} / \mathrm{l})$ was independently associated with increased risk of progression to critical disease or death among non-critical patients, as well as in-hospital mortality in patients with critical illness. Interestingly, in the same statistical model, diabetes mellitus, hypertension, chronic kidney disease, chronic obstructive pulmonary disease or cancer were not independent determinants of critical illness ${ }^{12}$. Furthermore, data from Hubei, China, shows that mortality was much lower (adjusted HR 0.14; 95\% CI 0.03-0.60) in hospitalized patients with COVID-19 and diabetes mellitus, with well-controlled glucose levels (glycaemic variability within $3.9-10.0 \mathrm{mmol} / \mathrm{l}$ ) compared with patients with diabetes mellitus and poorly controlled glucose levels (upper limit of glycaemic variability exceeding $10.0 \mathrm{mmol} / \mathrm{l})\left(\mathrm{REF}^{15}{ }^{15}\right.$. Taken together, these data indicate that good glucose control should be a critical target in patients with hyperglycaemia and COVID-19.

Of note, it cannot be excluded that hyperglycaemia during hospital admission for COVID-19 might simply be a marker of disease severity and not a modifiable risk factor that can alter outcome. In this respect, dexamethasone ${ }^{53}$ was found to improve clinical outcomes in COVID-19 in the RECOVERY trial, despite the fact that it might precipitate hyperglycaemia in some individuals. However, because large studies ${ }^{30,51}$ found an independent relationship of increased $\mathrm{HbA}_{1 \mathrm{c}}$ with severe COVID-19, it is reasonable to assume that good glucose control could improve the clinical outcomes in COVID-19.

Mendelian randomization analyses. Findings from observational studies investigating the independent relationships of obesity and parameters of impaired metabolic health with COVID-19 are partly supported by the genetically based approach of Mendelian random ization analysis. A study investigated, with Mendelian randomization, whether there is a causal effect of cardiometabolic traits on risk of severe COVID-19 (REF. ${ }^{54}$ ). Genome-wide association study summary data were used from a study with 1,610 patients with severe COVID19 with respiratory failure and 2,205 control individuals with no or mild COVID-19 symptoms ${ }^{55}$. A higher genetically proxied (based on genetic variants) BMI was associated with increased risk of severe COVID-19 (OR 1.75; 95\% CI 1.20-2.57). Interestingly, in that study, limited evidence was provided to support associations of genetically proxied lipid traits (that is, HDL-cholesterol, LDL-cholesterol or triglycerides), systolic blood pressure or T2DM susceptibility with risk of severe COVID-19. A limitation of this approach is that a Mendelian randomization study considers the lifelong effect of genetic variants that contribute to cardiometabolic traits, which is different from short-term measurement of specific parameters that might also strongly affect the outcome $e^{54}$. Although the authors explored the association of genetically proxied T2DM susceptibility with risk of sepsis, they were not able to explore genetically proxied T2DM itself, as this is a binary trait. Thus, they cannot exclude that a causal relationship between T2DM (or glycaemic control) and sepsis risk might exist.

\section{Cardiometabolic damage}

To clarify why some patients experience severe COVID-19, it is important to better understand viral-host interactions and, more specifically, which human tissues and organs are most strongly affected by SARS-CoV-2 infection. SARS-CoV-2 enters target cells by the coronavirus spike protein, which engages angiotensin-converting enzyme 2 (ACE2) as an entry receptor. Cell entry also requires priming of the spike protein by the cellular serine protease TMPRSS2 (REFS ${ }^{56-59}$ ). Quantification of the SARS-CoV-2 viral load of different human tissue samples revealed multiorgan tropism, and particularly high viral loads were found in the respiratory tract, and in myocardial, renal, neurological and gastrointestinal tissues ${ }^{60-65}$. Furthermore, expression of ACE2 and TMPRSS2 is found in human lung alveolar epithelial cells, nasal goblet secretory cells, cholangiocytes, colonocytes, oesophageal keratinocytes, gastrointestinal epithelial cells, pancreatic $\beta$-cells and renal proximal tubules and podocytes ${ }^{60-65}$. The mechanisms of interaction of SARS-CoV-2 with host cells and extrapulmonary manifestation of COVID-19 have been elegantly summarized and discussed ${ }^{8,65,66}$. Here we summarize the effect of SARS-CoV-2 infection on cardiometabolic relevant tissues and organs, particularly in obesity (FIG. 2).

Endotheliitis and hypercoagulopathy in COVID-19. Obesity is associated with hypercoagulability of the blood and an increased risk of thromboembolism. Mechanisms explaining this relationship involve chronic inflammation activating prothrombotic signalling pathways in platelets and other vascular cells and impaired fibrinolysis, mediated largely by increased production of plasminogen activator inhibitor 1 (PAI1) ${ }^{67}$. In obesity, expression of PAI1 is predominantly upregulated 


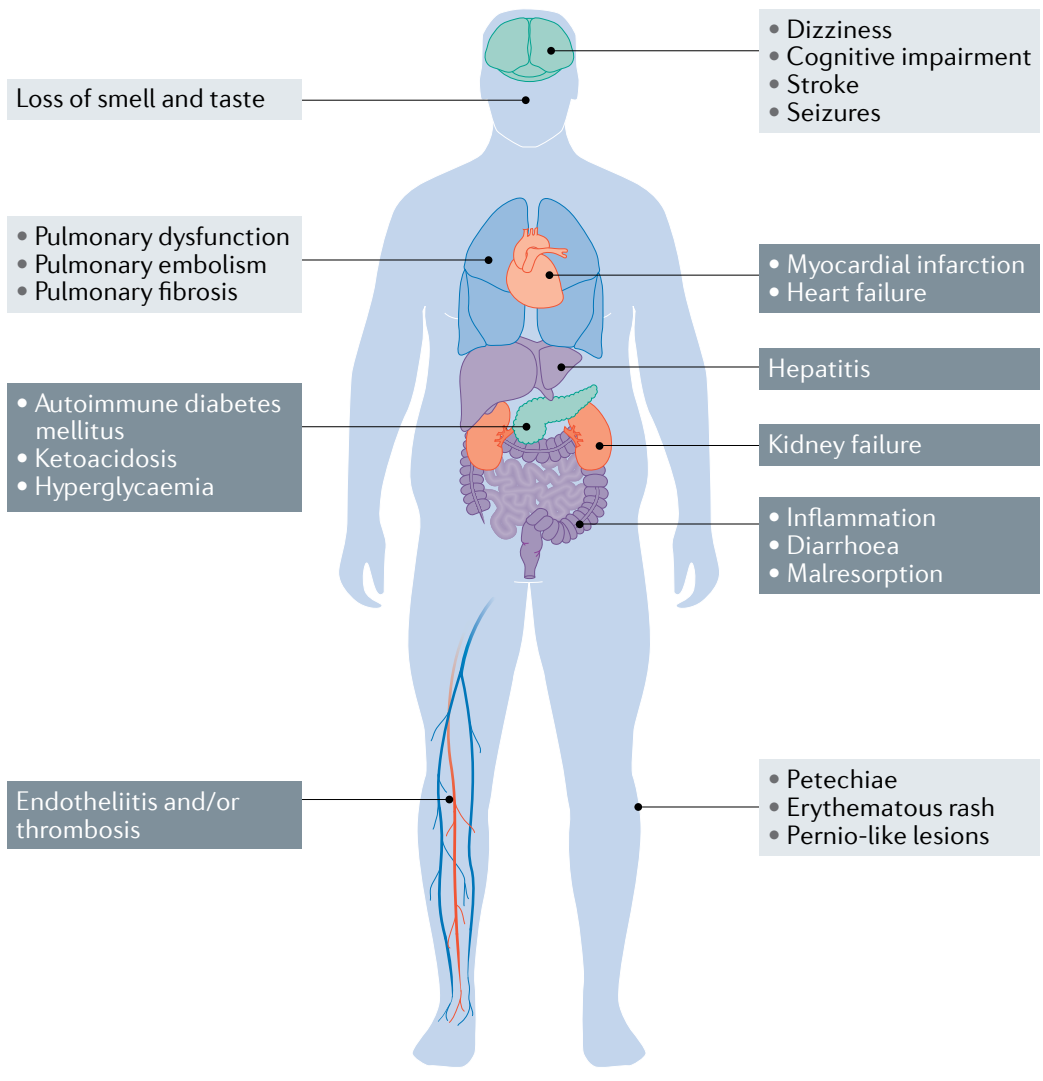

Fig. 2 | Pulmonary and extrapulmonary pathologies of COVID-19 and cardiometabolically relevant complications in patients with obesity. The pulmonary manifestations of coronavirus disease 2019 (COVID-19) caused by infection with severe acute respiratory syndrome coronavirus 2 , including pneumonia and acute respiratory distress syndrome, are well recognized ${ }^{3-5}$. Furthermore, neurological, gastrointestinal, dermatological and ophthalmological manifestations are being observed ${ }^{65}$. The cardiometabolic complications that can occur in patients with COVID-19 are highlighted in darker grey.

Endotheliitis

An inflammatory immune response within the endothelium of blood vessels.

Cytokine storm

A proinflammatory state characterized by release of multiple proinflammatory cytokines and chemokines in visceral adipose tissue, and plasma levels of PAI1 are elevated in patients with obesity or the metabolic syndrome $^{68,69}$. SARS-CoV-2 enters endothelial cells via ACE2 and induces endotheliitis and potentially thrombosis, not only in the lungs ${ }^{70}$, but also across vascular beds of different organs, thereby increasing the risk of thrombosis ${ }^{71}$. In COVID-19, microthrombi formation and microvascular dysfunction are observed, which might be particularly critical in obesity, visceral adiposity and impaired metabolic health, phenotypes that are generally considered as being characterized by a prothrombotic state.

Myocardial injury in COVID-19. SARS-CoV-2-induced endotheliitis and microvascular dysfunction are also relevant for the myocardium. The cytokine storm that is observed in severe COVID-19 (REF. ${ }^{72}$ ) is thought to result in vascular inflammation and atherosclerotic plaque instability, as well as in myocardial inflammation ${ }^{73-78}$. An acute COVID-19 cardiovascular syndrome can occur, which is characterized by an acute cardiac injury with cardiomyopathy, ventricular arrhythmias and haemodynamic instability in the absence of obstructive coronary artery disease ${ }^{75}$. The cause of this injury is uncertain but is suspected to be related to myocarditis, microvascular injury, systemic cytokine-mediated injury or stressrelated cardiomyopathy. ACE2 is highly expressed in arterial and venous endothelial cells, pericytes and also in cardiomyocytes. Therefore, acute cellular injury of cardiomyocytes caused by SARS-CoV-2 through ACE2-mediated entry and subsequent viral replication is considered important ${ }^{76-78}$. These pathologies can result in clinical manifestation in patients with COVID-19, such as acute coronary syndrome, acute myocardial injury without obstructive coronary artery disease, arrhythmias, heart failure with or without cardiogenic shock, pericardial effusion and thromboembolic complications ${ }^{75}$. Whether COVID-19 primarily induces CVD or whether cardiovascular complications are predominantly a consequence of severe COVID-19 is still unsolved ${ }^{77}$. Most probably, both pathogenic courses are relevant for COVID- 19 .

Renal injury in COVID-19. Related to impaired metabolic health, chronic kidney disease is both a cause for increased morbidity and mortality in cardiometabolic diseases, and a consequence (for example, resulting from hypertension, hyperglycaemia, insulin resistance and subclinical inflammation $)^{79,80}$. Thus, renal injury in COVID-19 could be very important, particularly for patients with obesity and impaired metabolic health. In patients with COVID-19, acute renal injury is often observed and is associated with increased mortality ${ }^{65,81-83}$. In the kidney, ACE2 is expressed in podocytes, mesangial cells, parietal epithelium of Bowman's capsule, proximal cell brush border and collecting ducts ${ }^{83}$. Furthermore, ACE2 is implicated in the kidneys in reducing glomerular and tubular damage and fibrosis ${ }^{83}$. Thus, increased entry of SARS-CoV-2 into renal cells, which results in infection and possibly reduced availability of the ACE2 receptor, together with SARS-CoV-2-induced microthrombi formation and microvascular dysfunction and pro-inflammatory cytokine expression, might explain the acute renal injury that is frequently observed in patients with COVID-19.

Hepatic injury in COVID-19. Liver dysfunction, particularly nonalcoholic fatty liver disease (NAFLD), is now accepted as a cause of impaired glucose and lipid metabolism, and as a consequence of obesity and impaired metabolic health ${ }^{84,85}$. Moreover, this close relationship of NAFLD with impaired glucose and lipid metabolism resulted in experts advocating a new definition for NAFLD, that is, metabolic associated fatty liver disease (MAFLD) ${ }^{86}$. The new definition more strongly supports hepatic steatosis being an important noncommunicable disease. In a small study from Wenzhou, China, 55 patients with COVID-19 aged $<60$ years with MAFLD were 1:1 matched by age, sex and obesity status to patients infected with SARS-CoV-2 without MAFLD; in this study, MAFLD was associated with a fourfold (OR 4.07; 95\% CI 1.20-13.79) increased risk of severe COVID-19 (REF. ${ }^{87}$ ). Furthermore, in a cohort of 310 patients with COVID-19 in Zhejiang Province, China, the fibrosis-4 index (adjusted OR 1.90; 95\% CI $1.33-2.72$ ) and the NAFLD fibrosis score (adjusted OR 2.57 ; $95 \%$ CI (1.73-3.82) were significantly associated 
with greater severity of COVID-19, independently of sex, obesity, diabetes mellitus and presence or absence of MAFLD ${ }^{88}$.

Thus, knowledge about the susceptibility of patients with liver disease to severe COVID-19 and any consequent hepatic injury is very important for patients with obesity and impaired metabolic health. In critically ill and hospitalized patients with COVID-19, markers of hepatocellular injury are frequently observed (14-53\% of patients ${ }^{66,89}$. Although several studies investigated the prognostic value of abnormal liver function test in patients with COVID-19 (for example, for disease progression, ICU admission, length of hospital stay and mortality), the results are inconclusive ${ }^{89}$. Single-cell RNA-sequencing studies in human liver identified ACE2 mRNA expressed in a subpopulation of cholangiocytes and only very limited or no expression in hepatocytes; expression was not observed in any other liver cell type $^{90,91}$. Furthermore, single-cell RNA-sequencing analysis in human liver samples did not predict hepatocyte infection by SARS-CoV-2 (REF. ${ }^{91}$ ). In addition, data from a US clinical study including 1,827 hospitalized patients with COVID-19 indicated that any liver damage was predominantly hepatocellular, rather than cholestatic, which suggests no direct cytopathic effects by SARS-CoV-2 in the liver ${ }^{2}$.

Of note, in whole liver samples, ACE2 and TMPRSS2 mRNA expression was increased in patients with T2DM and increased liver fat content ${ }^{93}$. Furthermore, cytokine storm and hypoxia-induced organ damage ${ }^{66,94}$ might be very important in the liver. In this respect, endotheliitis has also been observed in the liver of patients with COVID-19 (REFS ${ }^{71,95,96}$ ). Furthermore, fibrin microthrombi were found in liver sinusoids. In addition, in liver biopsy samples taken at autopsy from individuals who died of COVID-19, massive dilation of portal vein branches, luminal thrombosis, portal tract fibrosis and microthrombi in the sinusoids was observed ${ }^{71,95,96}$.

Gastrointestinal injury in COVID-19. Compared with several other human tissues, by far the highest expression of ACE2 was found in the small intestine, followed by the colon and the duodenum ${ }^{90}$. Furthermore, in small intestinal organoids, enterocytes were readily infected by SARS-CoV (the virus that causes severe acute respiratory syndrome, SARS) and SARS-CoV-2, and these enterocytes produced infectious viral particles ${ }^{97}$. In addition, gastrointestinal symptoms are observed in a subset of patients with COVID-19 $\left(\right.$ REF $\left.^{98}\right)$.

The gut has a well-established and important role in the regulation of adipose tissue mass and of glucose and lipid metabolism. A Western diet induces dysregulation of the intestinal microbiome composition, resulting in disruption of the intestinal barrier and translocation of gut microbiota, metabolites and activated immune cells into the circulation ${ }^{99,100}$. Predominantly via such a leaky gut, bacteria-derived products are considered to contribute to the pathogenesis of metabolic diseases, inducing adipose tissue inflammation, hepatic steatosis and hepatic inflammation ${ }^{100,101}$. In mice, feeding of a high-fat diet was found to induce a proinflammatory condition in the gut, which was associated with an increase in
IL-17-producing cells, an increase in IFN $\gamma$-producing T helper $1\left(\mathrm{~T}_{\mathrm{H}} 1\right)$ cells and CD8 ${ }^{+} \mathrm{T}$ cells, and a concomitant reduction in regulatory $\mathrm{T}$ cells ${ }^{102}$. In patients with COVID-19, an increase in IL-17-producing $\mathrm{T}_{\mathrm{H}} 17$ cells and high cytotoxicity of $\mathrm{CD} 8^{+} \mathrm{T}$ cells are observed in the peripheral blood ${ }^{103}$, which are thought to have important roles in the cytokine storm of COVID-19 (REFS $\left.{ }^{104-106}\right)$. Thus, very similar proinflammatory characteristics seem to be present in the gut of patients with severe COVID-19 and individuals with metabolically unhealthy obesity who consume a Western diet.

Pancreatic injury in COVID-19. Finally, among the cardiometabolically relevant organs, the pancreas is a crucial target of SARS-CoV-2. Applying two single-cell RNA-sequencing data sets, a study found that ACE2 was expressed in both the exocrine glands and the islets ${ }^{107}$. In addition, in that study few patients (1.85\%) with mild COVID-19 had increased levels of amylase and lipase. However, in patients with severe COVID-19, 17.91\% of the patients had increased levels of amylase and $16.41 \%$ had increased levels of lipase ${ }^{107}$. CT scans of patients with severe COVID-19 showed changes in the pancreas, mainly focal enlargement of the pancreas or dilation of the pancreatic duct, without acute necrosis, and some patients had symptoms of acute pancreatitis ${ }^{107}$.

In respect of endocrinological complications of severe COVID-19, islet cell damage is critical. A 2010 study found that ACE2 protein was strongly expressed in the pancreatic islets ${ }^{108}$. Furthermore, in a study of patients with SARS, SARS-CoV-associated damage occurred in the kidney, heart, lung and endocrine part of the pancreas. In addition, during a 3-year follow-up period, a higher incidence of diabetes mellitus was found in patients who recovered from SARS (who were not treated with glucocorticoids), compared with uninfected control individuals ${ }^{108}$.

The risk of $\beta$-cell damage induced by SARS-CoV and SARS-CoV-2 might also result in acute complications. In this respect, several cases of newly diagnosed diabetes mellitus were reported in patients with COVID-19, with and without pre-existing comorbidities, which were often accompanied by ketoacidosis ${ }^{109}$. In a Chinese study, SARS-COV-2 infection was associated with ketoacidosis. Furthermore, from a total of 42 patients in this study with COVID-19-associated ketosis and ketoacidosis, 27 patients had ketoacidosis without a diagnosis of diabetes mellitus ${ }^{110}$. Furthermore, a London study identified 35 patients with COVID-19 who presented with diabetic ketoacidosis (DKA) (31.4\%), mixed DKA and hyperosmolar hyperglycaemic state (HHS) (37.1\%), HHS (5.7\%) or hyperglycaemic ketosis $(25.7 \%)$. In that study a very high prevalence $(80 \%)$ of patients with T2DM presented with DKA, which indicates acute insulinopenia in patients with COVID-19 and T2DM. Furthermore, 5.7\% of the 35 patients with COVID-19 had newly diagnosed diabetes mellitus ${ }^{111}$. Thus, insulin resistance and insulinopenia in a subset of critically ill patients with COVID-19 might result in an increased incidence of diabetes mellitus and a complicated course in patients with diagnosed diabetes mellitus ${ }^{12,113}$. This issue is currently under intense investigation ${ }^{114}$. 


\section{Long-term effects of the pandemic}

Data are just emerging regarding the effect of the COVID-19 pandemic on the prevalence and incidence of obesity and cardiometabolic diseases during a longterm follow-up (FIG. 3). Direct effects might include organ dysfunction in affected patients. However, indirect effects could also occur, such as effects on health care for patients without COVID-19 or effects on health-related behaviour, which is strongly dependent on regional lockdown measures and public perception and/or fear of infection.

Effects of the COVID-19 pandemic on the obesity pandemic. When investigating the long-term effects of the COVID-19 pandemic, it is important to separate the health consequences of SARS-CoV-2 infection from the effect of the COVID-19 pandemic on behaviour and lifestyle of non-infected people. After the SARS pandemic in 2003, physicians observed a high rate of patients with SARS who continued to have clinical symptoms weeks and months after they recovered from the acute infection. For example, one study investigated health-care workers from Toronto, Canada, who remained unable to return to their former occupation

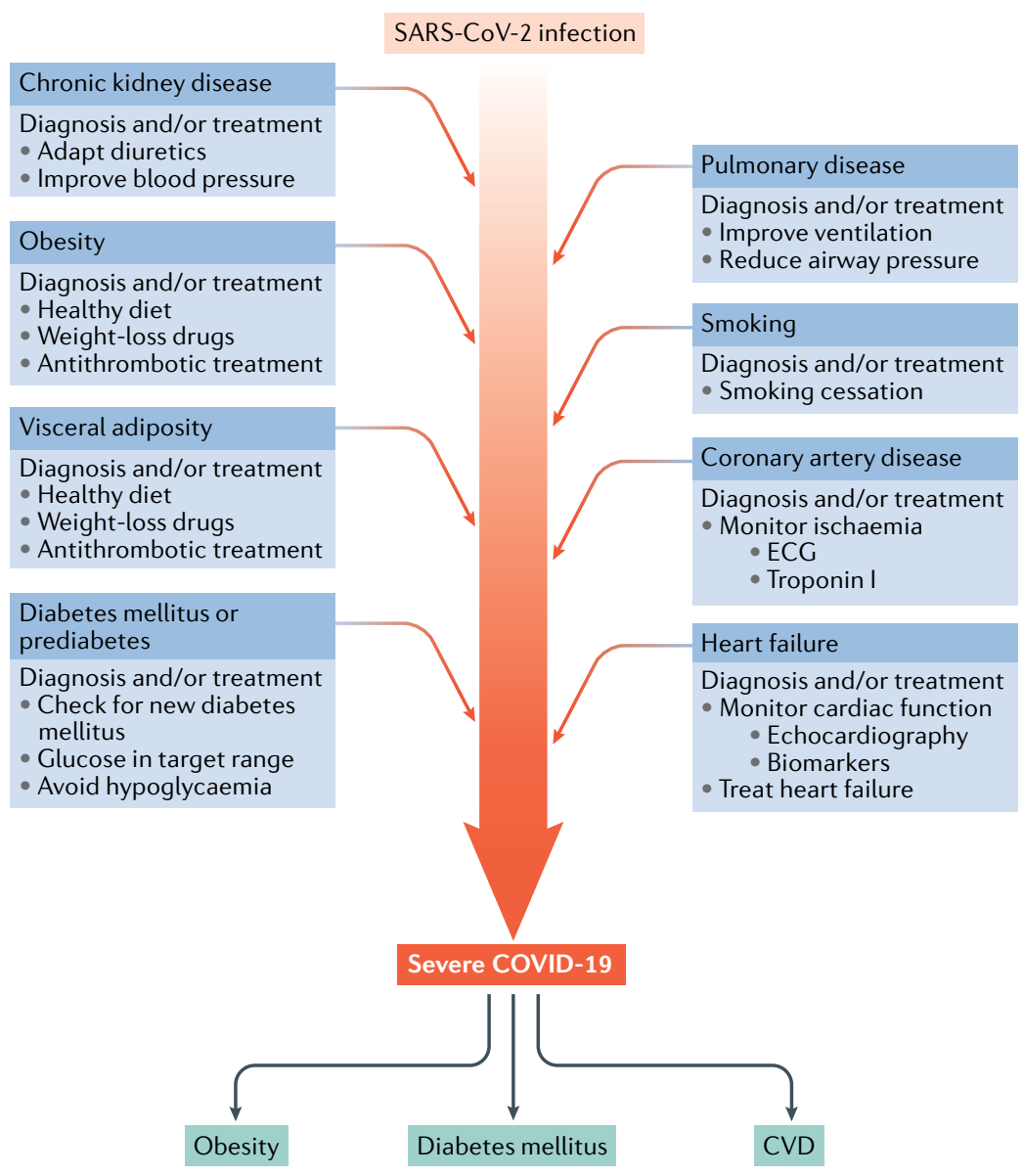

Fig. 3 | Selected causes, consequences and treatment of severe COVID-19.

Important risk factors for a severe course of coronavirus disease 2019 (COVID-19) and suggestions for their treatment during severe acute respiratory syndrome coronavirus 2 (SARS-CoV-2) infection are depicted. Furthermore, the figure highlights that obesity and cardiometabolic diseases could be a consequence of a severe course of COVID-19. CVD, cardiovascular disease; ECG, electrocardiogram. after a mean 19.8 months (range 13-36 months) following SARS. In these patients, a very high rate of a chronic post-SARS syndrome was observed, which was characterized by chronic fatigue, pain, weakness, depression and sleep disturbance ${ }^{115}$. Furthermore, in a multicentre prospective follow-up study of 52 survivors of Middle East respiratory syndrome (MERS, caused by the related MERS-CoV) in the Republic of Korea, $48 \%$ and $33 \%$ of the patients had clinically relevant chronic fatigue after 12 (referred to as T1) and 18 (referred to as T2) months of follow-up, respectively. Post-traumatic stress symptoms were found in $42 \%$ of patients at $\mathrm{T} 1$ and $27 \%$ at $\mathrm{T} 2$, and clinically relevant depressive symptoms were found in $27 \%$ of patients at T1 and $17 \%$ at T2. Among these patients, chronic fatigue was found to induce post-traumatic stress symptoms partly through provoking depression ${ }^{116}$. A meta-analysis of 28 studies, which included 2,820 patients with SARS or MERS, examined long-term outcomes and reported high rates of posttraumatic stress disorder (38\%), depression (33\%) and anxiety (30\%) at 6 months following illness, as well as pulmonary dysfunction, reduced exercise tolerance and reduced health-related quality of life ${ }^{117,118}$.

In patients who had recovered from COVID-19 after having been hospitalized in Rome, Italy, $87.4 \%$ reported persistence of at least one symptom, particularly fatigue and dyspnoea, when assessed after a mean of 60.3 (s.d. 13.6) days after symptom onset ${ }^{119}$. Of note, in young healthy men, a decrease in daily physical activity for only 2 weeks results in a loss of muscle mass and an increase in visceral adipose mass, insulin resistance and increased plasma levels of triglyceride ${ }^{120}$. Therefore, physical deconditioning and sarcopenia from bed rest and physical inactivity during COVID-19 might strongly impair metabolism in many patients. Finally, because there is a bidirectional relationship of anxiety and depression with obesity $^{121}$, post-COVID-19 depression, chronic fatigue and post-traumatic stress symptoms might induce weight gain.

COVID-19 could also influence obesity development in people who are not infected by SARS-CoV-2. For example, among 123 patients with obesity from a clinic in Texas, two patients tested positive for SARS-CoV-2 and $14.6 \%$ reported symptoms. However, a total of $72.8 \%$ of patients reported increased anxiety and $83.6 \%$ reported increased depression since stay-at-home orders were initiated. Furthermore, $69.6 \%$ of the patients reported more difficulty in achieving weight-loss goals. More specifically, during lockdown conditions, patients spent less time exercising (47.9\%) and at a decreased intensity (55.8\%), increased their stockpiling of food $(49.6 \%)$ and reported increased stress eating $(61.2 \%)^{122}$.

A decrease in physical activity in particular is being observed during the COVID-19 pandemic. For example, based on estimates of step counts in more than 30 million people in Europe, a reduction in physical activity ranging between $7 \%$ and $38 \%$ is being assumed during the pandemic ${ }^{123,124}$. The complex of physical, emotional, social and financial challenges that individuals face during the pandemic also affects food purchasing and consumption habits. Positive experiences in terms of household food behaviours (for example, home-cooking, 
food sharing and increased attention to diet) during lockdowns are contrasted by exacerbated food insecurity and decreased affordability, particularly among vulnerable groups ${ }^{125}$. Persistent food insecurity is associated with a sustained diet of cheap and energy-dense foods, which could lead to a rise in rates of obesity ${ }^{126}$. In addition to changes in lifestyle, the COVID-19 pandemic could also considerably affect the treatment of obesity. For example, a delay in bariatric surgery for patients with morbid obesity has been observed ${ }^{127}$. In Italy, elective bariatric and metabolic surgery was cancelled on 21 February 2020 and it was gradually restarted on 4 May $2020\left(\right.$ REF. $\left.^{128}\right)$. These data suggest that the COVID19 pandemic considerably affects patients with obesity, regardless of infection status ${ }^{129,130}$.

Effects of the COVID-19 pandemic on cardiometabolic health. Novel data suggest that persistent myocardial injury might occur in patients who have recently recovered from COVID-19. A study from Germany investigated the characteristics, cardiac blood markers and cardiovascular MRI data of 100 patients who had recovered from COVID-19, as well as an age-matched and sexmatched control group of 50 healthy volunteers and 57 cardiometabolic risk factor-matched individuals ${ }^{131}$. In that study, cardiovascular MRI revealed cardiac involvement in $78 \%$ and ongoing myocardial inflammation in $60 \%$ of the patients who had recovered from COVID-19, independent of pre-existing conditions, or the severity and overall course of the acute illness, or time from the original diagnosis ${ }^{131}$. These data support the need for further investigation of the long-term CVD consequences of COVID-19.

With respect to diabetes mellitus, an increase in its prevalence and a worsening of glucose control is expected. A study from India analysed demographic and clinical data from 100 apparently healthy household members (related or unrelated) of patients with T2DM, which were collected for 49 days of lockdown. In that study, a trend for weight gain was observed in $40 \%$ of the cohort, with $16 \%$ of the population experiencing a $2.1-5.0 \mathrm{~kg}$ increase in weight. Furthermore, an increase in the American Diabetes Association risk score occurred in $7 \%$ of the population ${ }^{132}$. A second study by the same authors investigated the effect of lockdown duration on glycaemic control and complications related to diabetes mellitus. A simulation model was generated using glycaemic data from previous disasters (taken as similar in effect to the current lockdown) on baseline $\mathrm{HbA}_{1 \mathrm{c}}$ and complications related to diabetes mellitus from an India-specific database. The researchers found that the predicted relative increment in $\mathrm{HbA}_{1 \mathrm{c}}$ from baseline to the end of 30 days and 45 days of lockdown was projected as $2.26 \%$ and $3.68 \%$, respectively. Furthermore, they estimated that the percentage increase in rates of diabetic complications at the end of a 30-day lockdown amounted to $2.8 \%$ for non-proliferative diabetic retinopathy, $2.9 \%$ for proliferative diabetic retinopathy, $1.5 \%$ for retinal photocoagulation, $9.3 \%$ for microalbuminuria, $14.2 \%$ for proteinuria, $2.9 \%$ for peripheral neuropathy, $10.5 \%$ for lower extremity amputation, $0.9 \%$ for myocardial infarction, $0.5 \%$ for stroke and $0.5 \%$ for infections ${ }^{133}$.
It remains to be seen whether such increases will be observed after the COVID-19 pandemic.

Importantly, the COVID-19 pandemic is thought to affect the behaviour of patients and their health-care providers $^{134,135}$. For example, in children and adolescents with T1DM that was newly diagnosed during the COVID-19 pandemic in Germany, an alarming increase in the incidence of DKA was observed. The researchers found a higher incidence of DKA compared with the previous 2 years ( $44.7 \%$ in 2020 versus $24.5 \%$ in 2019 ; adjusted risk ratio 1.84 (95\% CI 1.54-2.21) versus $24.1 \%$ in 2018; adjusted risk ratio 1.85 (95\% CI 1.54-2.24) $)^{136}$. The underlying causes were hypothesized to be multifactorial, including reduced access to medical services, fear of approaching the health-care system and more complex psychosocial factors ${ }^{136}$.

During the first months of the COVID-19 pandemic, the numbers of deaths unrelated to COVID-19 increased ${ }^{137}$. This change could partly be explained by a substantial increase in the number of avoidable cancer deaths; for example, as suggested for the UK, an increase in cancer-related death is to be expected as a result of diagnostic delays due to the COVID-19 pandemic ${ }^{138}$. Moreover, CVD-associated morbidity and mortality are expected to increase. For example, a UK study reported a statistically significantly lower admission rate for acute heart failure during a study period between 2 March and 19 April 2020, when compared with a pre-COVID-19 cohort or the corresponding time periods in 2017-2019 $\left(\right.$ REF $\left.^{139}\right)$. Whether the incidence of acute heart failure has actually declined is unclear; however, observations of a decline in acute coronary syndrome admissions in Austria since the outbreak of COVID-19 support the suggestion that patients showed a reluctance to attend hospitals when the symptoms of cardiac dysfunction occurred $^{140}$. It remains to be investigated whether such delays in seeking medical care will be associated with worse long-term outcomes. Finally, during the COVID-19 pandemic, a large decline in the level of habitual physical activity was observed in patients with heart failure ${ }^{141}$, which could also considerably affect heart health in patients with heart disease.

\section{Treating obesity in the COVID-19 pandemic}

Considering the strong effects of overweight, obesity and impaired metabolic health on the course of COVID19 , achieving reductions in adipose tissue mass and improvements in metabolic health is crucial. Here, two questions are relevant. First, how should we manage patients who are infected with SARS-CoV-2 to achieve this goal? Second, what are the best strategies for this purpose in people who have recovered from COVID-19 or who have not been infected yet?

Treatment of patients with metabolically unhealthy obesity and COVID-19. Supportive and intensive care treatment of patients with COVID-19 is well established ${ }^{8}$. Furthermore, encouraging new results from clinical trials with antiviral drugs (remdesivir) ${ }^{142}$ and immunomodulatory drugs (dexamethasone) ${ }^{53}$ in patients with severe COVID-19 have been published. However, as discussed by Clifford Lane and Anthony S. Fauci ${ }^{143}$, despite the 
Mediterranean diet

A diet characterized by fairly

high consumption of olive oil legumes, unrefined cereals,

fruits, vegetables and fish and moderate consumption of

dairy products. expected reduction in morbidity and mortality that might occur when these drugs are more often used, many people with COVID-19 will still die. Thus, there is hope that new therapeutic agents, such as monoclonal antibodies, more selective immunosuppressive agents and vaccines against this disease ${ }^{8,143}$, will help to lower the number of complications and mortality in patients with COVID-19.

In patients with metabolically unhealthy obesity, close monitoring of the clinical development of COVID-19 is necessary during the acute phase of infection, owing to the increased risk of a complicated course. Furthermore, biomarkers of pulmonary, cardiac, liver and renal function, as well as of glycaemic control, should be used early in the disease course to assess the progression of the disease $e^{75,112,113}$. In general, the acute COVID-19 cardiovascular syndrome should be managed by a multidisciplinary team that includes infectious disease consultation to help guide therapy selection $^{75}$. For diabetes mellitus, treatment should aim for reduction of hyperglycaemia into the target range, using, wherever possible, drugs that have a low risk of hypoglycaemia, lactic acidosis and ketoacidosis, and fluid retention ${ }^{112,113}$.

Treatment of people with metabolically unhealthy obesity without COVID-19. Owing to the striking resemblance between the mechanisms by which obesity and impaired metabolic health affect the risk of cardiometabolic diseases and severe COVID-19 (REFS ${ }^{16,22,40,41,65,66}$ ), preventive measures taken to reduce the risk of cardiometabolic diseases could also decrease the risk of severe COVID19. Furthermore, obesity and impaired metabolic health might adversely influence the efficacy of vaccines against SARS-CoV-2 (REFS $\left.{ }^{144-147}\right)$. For example, patients with obesity and/or T2DM show immune senescence and accelerated ageing of the immune system, particularly of the $\mathrm{CD}^{+}$and $\mathrm{CD}^{+} \mathrm{T}$ cell compartments ${ }^{148,149}$. In addition, reduced influenza vaccine efficacy has been observed in people with obesity ${ }^{150-153}$. One study reported that although people with obesity do not have an impaired initial response to influenza vaccination, the percentage of influenza-activated $\mathrm{CD}^{+} \mathrm{T}$ cells (which kill virus-infected cells) and two markers of functional $\mathrm{CD}^{+} \mathrm{T}$ cell activity (IFN $\gamma$ and granzyme $\mathrm{B}$ ) were found to decrease substantially 12 months after vaccination in people with obesity, compared with individuals with normal weight ${ }^{151}$. Furthermore, in 7 patients with T1DM and 41 patients with $\mathrm{T} 2 \mathrm{DM}$, a higher $\mathrm{HbA}_{1 \mathrm{c}}$ tended to be associated with a lower immune response to an influenza A (H1N1) vaccine, independently of age, sex and $\mathrm{BMI}^{154}$. Therefore, in the efficacy analyses of the results of the ongoing vaccine trials, measures of obesity and hyperglycaemia need to be carefully taken into account.

Altogether, preventive measures for obesity and cardiometabolic diseases need to be taken at patient level and in the public health sector. When targeting obesity and visceral obesity, most clinical guidelines recommend an initial loss of $5-8 \%$ of total body weight for individuals with overweight or obesity, to prevent cardiometabolic diseases ${ }^{155,156}$. However, increased weight loss might be necessary to decrease this risk, particularly for people with more severe obesity (class II (BMI $35.0-39.9 \mathrm{~kg} / \mathrm{m}^{2}$ ) and III $\left.\left(\mathrm{BMI} \geq 40 \mathrm{~kg} / \mathrm{m}^{2}\right)\right)^{157}$. In people with obesity, lifestyle intervention, including a reduction in caloric intake and an increase in physical activity, is effective in decreasing adipose tissue mass and the risk of cardiometabolic diseases ${ }^{155,156}$. The PREDIMED trial demonstrated that an adapted ad libitum Mediterranean diet over a median follow-up of 4.8 years reduced the risk of cardiovascular events by $\sim 30 \%$ in people who were at high cardiovascular risk, but with no cardiovascular disease at enrolment, compared with a control diet, despite having little effect on body weight ${ }^{158,159}$. Therefore, people with metabolically unhealthy obesity might be advised to switch to a Mediterranean diet to reduce their cardiometabolic risk.

Evidence is accumulating about the beneficial cardiometabolic effects of a ketogenic (that is, high-fat and very-low-carbohydrate) diet. Ketones have very well-documented neuroprotective, hepatoprotective and cardioprotective effects ${ }^{160,161}$. Moreover, ketogenic diets were found to alter the human and mouse gut microbiome, distinct from a high-fat diet. Importantly, the ketogenic diet decreased the levels of intestinal pro-inflammatory $\mathrm{T}_{\mathrm{H}} 17$ cells in mice ${ }^{162}$, the cell type that is thought to largely contribute to the proinflammatory response observed in COVID-19 (REFS ${ }^{104-106}$ ). Thus, it is worth investigating whether a ketogenic diet as a weight-loss strategy might be superior to other weight-loss strategies in the context of COVID-19. However, as a ketogenic diet might increase the risk of $\mathrm{DKA}^{163}$, it should not be continued in patients with diabetes mellitus who are infected with SARS-CoV-2.

At the patient level, the first steps to reduce body adipose tissue mass and improve metabolic health are lifestyle counselling to implement an energy deficit, healthy nutrition and to increase physical activity ${ }^{164}$. If these measures are not effective, pharmacological treatment should be started as an adjunct to the aforementioned lifestyle intervention. Medications can be considered in adults who have a BMI $\geq 30 \mathrm{~kg} / \mathrm{m}^{2}$ or a BMI of $27-29 \mathrm{~kg} / \mathrm{m}^{2}$ with at least one weight-related coexisting condition ${ }^{165-167}$. In patients without T2DM, approved medications to reduce elevated body weight include orlistat, phentermine, phentermine-topiramate, naltrexone-bupropion and liraglutide ${ }^{165-167}$. In patients with obesity and T2DM, glucagon-like peptide 1receptor agonists and sodium-glucose cotransporter 2 inhibitors should preferentially be used, because they were shown to have cardiovascular and heart failure benefits that were also associated with weight loss ${ }^{168}$. For patients with severe obesity or for patients with obesity who cannot achieve the recommended amount of weight loss and/or the improvement in metabolic health, bariatric surgery should be considered. In patients with obesity, bariatric surgery is very effective in reducing adipose tissue mass and lowering the long-term risk of cardiometabolic diseases and all-cause mortality, compared with weight-matched non-surgical patients. Thus, bariatric surgery could be an important therapeutic option in many people with severe obesity, particularly during the COVID-19 pandemic ${ }^{129}$ (FIG. 4).

To combat the obesity pandemic, strong measures should also be taken in the public health sector, 
a

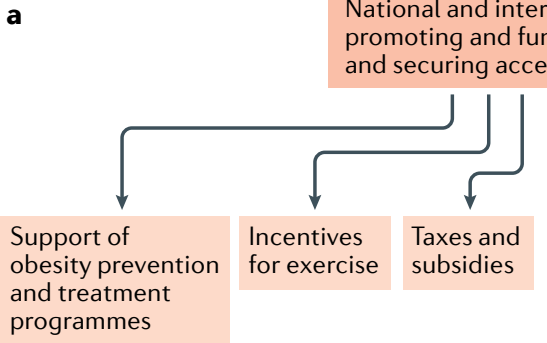
promoting and funding weight loss and securing access to healthy foods

b

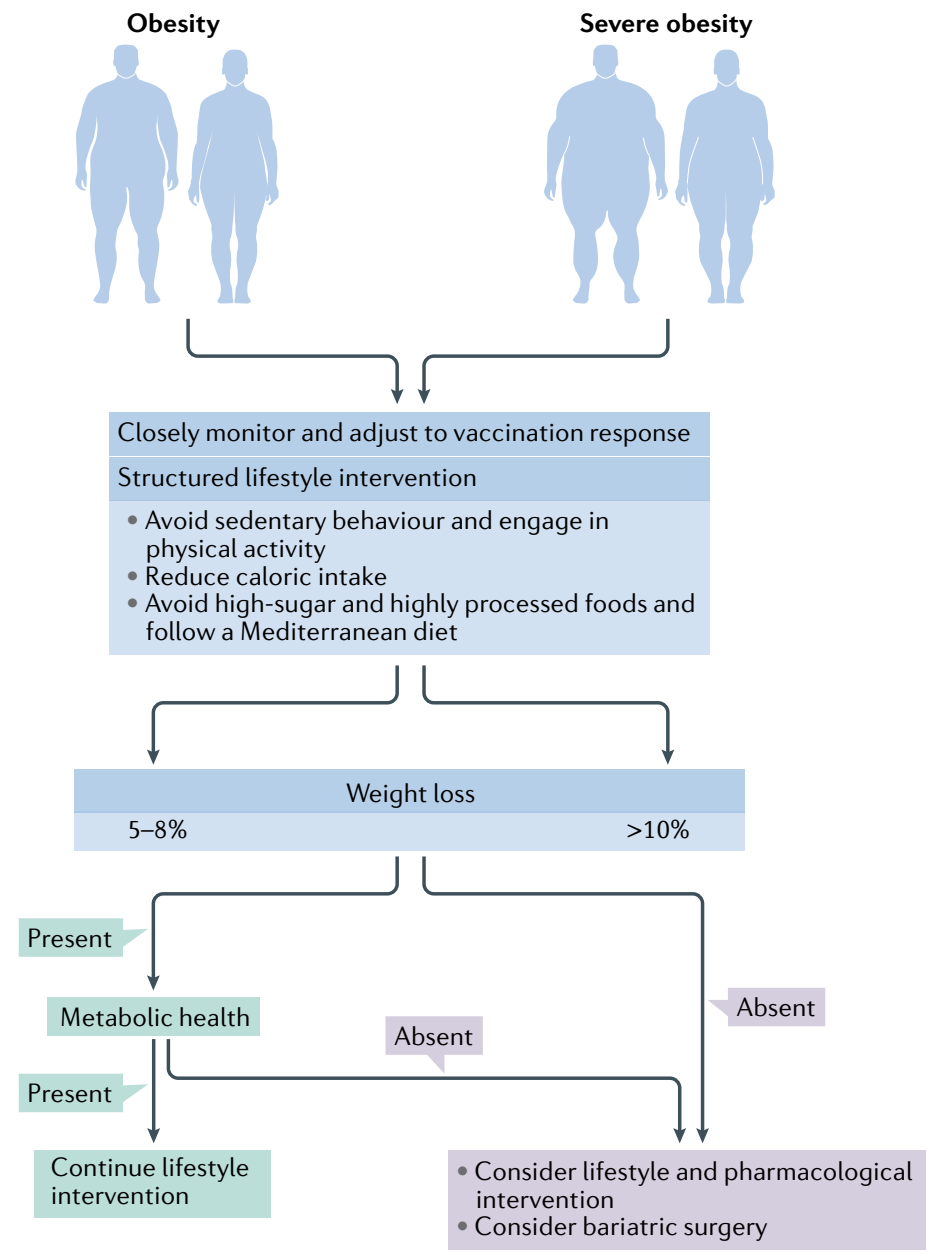

Fig. 4 | Political and patient level measures to prevent and treat obesity and impaired metabolic health. a| Political measures to promote weight loss and access to healthy foods should include different instruments, for example, related to nutrition education, food quality standards in schools, economic instruments and nutrition labelling. $\mathbf{b} \mid$ Patient-level measures to treat obesity and impaired metabolic health should define different targets of weight loss by lifestyle intervention depending on the degree of obesity. If these measures are not effective in reducing body weight and/or bringing about metabolic health, pharmacological treatment should be started as an adjunct to the aforementioned lifestyle intervention, and bariatric surgery might be necessary in some patients. schools and employers to implement safety measures during the COVID-19 pandemic. Furthermore, governments should help organizations that provide physical activity programmes and schools to find new ways to ensure that physical activity levels can be maintained and increased. In addition, governments should supply incentives to support an active lifestyle. Importantly, the prevalence of obesity and impaired metabolic health is particularly elevated in people with low socioeconomic status and in some ethnic groups ${ }^{169}$. As such, politicians and health-care providers should use diverse ways of communication specifically to reach out to these communities, and should consider policies that increase access to sport and leisure facilities, and healthy foods, for all.

Examples of how food policies could be implemented to more effectively prevent obesity at the population level were suggested in a $2015 \operatorname{article}^{170}$. A range of disciplines need to be integrated (for example, politics, psychology, economics and public health nutrition) to develop a theory of change to understand how food policies work. Here the interaction between human food preferences and the environment in which those preferences are learned, framed and re-evaluated is critical. Such food policies involve school settings, economic instruments and nutrition labelling. Furthermore, they need to be accompanied by incentives for an increase in physical activity (FIG. 4).

As an example of such a coordinated effort on the political level, the UK government initiated a national campaign to encourage millions of adults to kick start their health and reduce their risk of serious illness, including COVID-19 (REF. ${ }^{171}$ ). This campaign is based on the observation that people with obesity are considerably more likely to become seriously ill and be admitted to intensive care with COVID-19 compared with those with a healthy BMI. The campaign provides access to several apps and tools to help people stay in shape and make healthier food choices to prevent future weight gain. Furthermore, it includes TV advertisements, digital, print, radio and out of home advertising, and content across social media. In addition, press release and partnership activity will take place to motivate people to get active, eat better, drink less alcohol and quit smoking ${ }^{171}$. Finally, public communication of the increased risk of a severe COVID-19 that is brought about by obesity, such as is being done by the British Prime Minister Boris Johnson ${ }^{172}$, might be very effective in reaching many people and motivating them to lose weight.

Besides such educational efforts, governments should clearly admit their responsibility to implement comprehensive food policies to effectively reduce overweight and obesity in the general population, including necessary legislative measures ${ }^{173}$. Using the UK example, the campaign mentioned above is part of a national strategy including several other measures, for example banning advertisements for unhealthy foods, restriction on price incentives for such foods and clear food labelling; however, this strategy has still been criticized for its strong focus on individual responsibility ${ }^{174,175}$. Evidence-based public health nutrition interventions to fight the obesity pandemic exist ${ }^{169}$, and more than ever it is time to take this issue seriously. 
Importantly, further research is needed to better understand the variability in the health response to diet, particularly during the COVID-19 pandemic. To this end, Griffin P. Rodgers and Francis S. Collins from the National Institutes of Health (NIH) highlighted the 2020-2030 Strategic Plan for NIH Nutrition Research. They discussed that it is important to explore and understand how diet and nutritional status modify the immune response. Furthermore, this knowledge could help explain some of the variability in COVID-19 morbidity and mortality ${ }^{176}$. Funding within this programme includes research that helps to better understand the role of nutrition in improving health and reducing the burden of disease throughout life and across generations. For example, interactions of nutrition with other potentially modifiable exposures such as the microbiome will be investigated as well as how to use this holistic knowledge to develop and implement actionable recommendations ${ }^{177}$.

\section{Conclusions}

Based on data from large studies that investigated relationships of comorbidities with the course of COVID-19 using multivariate adjustment, obesity emerged as a strong and independent determinant of increased risk of morbidity and mortality in patients infected with SARS-CoV-2. Furthermore, novel data suggest that visceral obesity and hyperglycaemia in the non-diabetic and diabetic range could also be important independent risk factors for severe COVID-19. In addition, as obesity and diabetes mellitus have been found to impair the development of immunological memory (for example, after influenza vaccination), it cannot be excluded that obesity and hyperglycaemia might also negatively affect the efficiency of a SARS-CoV-2 vaccine. These relationships, as well as the knowledge that metabolic processes largely determine the course of COVID-19, suggest that treating obesity and cardiometabolic complications might be very effective in overcoming acute SARS-CoV-2 infection, and also in reducing the risk of post-COVID-19 cardiometabolic diseases and obesity. Weight loss and improvement of metabolic health in people with obesity and/or those who are metabolically unhealthy might help them to better cope with COVID-19. Newly launched national and international programmes at the political level and in the public health sector, as well as projected novel research funding are more than welcome to help achieve this important goal.

\section{Published online 21 January 2021}

1. World Health Organization. COVID-19 Weekly Epidemiological Update 22 December 2020 https://www.who.int/publications/m/item/weeklyepidemiological-update---22-december-2020 (2020).

2. Hauser, A. et al. Estimation of SARS-CoV-2 mortality during the early stages of an epidemic: a modeling study in Hubei, China, and six regions in Europe. PLoS Med. 17, e1003189 (2020).

3. Goyal, P. et al. Clinical characteristics of Covid-19 in New York City. N. Engl. J. Med. 382, 2372-2374 (2020).

4. Grasselli, G. et al. Risk factors associated with mortality among patients with COVID-19 in intensive care units in Lombardy, Italy. JAMA Intern. Med. 180 1345-1355 (2020).

5. Gupta, S. et al. Factors associated with death in critically ill patients with coronavirus disease 2019 in the US. JAMA Intern. Med. 180, 1-12 (2020).

6. Docherty, A. B. et al. Features of 20133 UK patients in hospital with covid-19 using the ISARIC WHO Clinical Characterisation Protocol: prospective observational cohort study. Br. Med. J. 369, m 1985 (2020).

7. Karagiannidis, $C$. et al. Case characteristics, resource use, and outcomes of 10021 patients with COVID-19 admitted to 920 German hospitals: an observational study. Lancet Respir. Med. 8, 853-862 (2020).

8. Wiersinga, W. J., Rhodes, A., Cheng, A. C., Peacock, S. J. \& Prescott, H. C. Pathophysiology, transmission, diagnosis, and treatment of coronavirus disease 2019 (COVID-19): a review. JAMA 324, 782-793 (2020).

9. Wu, Z. \& McGoogan, J. M. Characteristics of and important lessons from the coronavirus disease 2019 (COVID-19) outbreak in china: summary of a report of 72,314 cases from the Chinese Center for Disease Control and Prevention. JAMA 323, 1239-1242 (2020).

10. Simonnet, A et al. High prevalence of obesity in severe acute respiratory syndrome coronavirus-2 (SARS-CoV-2) requiring invasive mechanical ventilation. Obesity 28, 1195-1199 (2020).

11. Petrilli, C. M. et al. Factors associated with hospital admission and critical illness among 5279 people with coronavirus disease 2019 in New York City: prospective cohort study. Br. Med. J. 369, m1966 (2020).

12. Wu, J. et al. Elevation of blood glucose level predicts worse outcomes in hospitalized patients with COVID-19: a retrospective cohort study. BMJ Open Diabetes Res. Care 8, e001476 (2020).

13. Wang, S. et al. Fasting blood glucose at admission is an independent predictor for 28-day mortality in patients with COVID-19 without previous diagnosis of diabetes: a multi-centre retrospective study. Diabetologia 63, 2102-2111 (2020).

14. Smith, S. M. et al. Impaired glucose metabolism in patients with diabetes, prediabetes and obesity is associated with severe COVID-19. J. Med. Virol. https://doi.org/10.1002/jmv.26227 (2020).

15. Zhu, L. et al. Association of blood glucose control and outcomes in patients with COVID-19 and pre-existing type 2 diabetes. Cell Metab. 31, 1068-1077 (2020). This important study shows that in patients with type 2 diabetes mellitus and COVID-19, good glucose control near the target range was associated with decreased mortality.

16. Stefan, N., Birkenfeld, A. L., Schulze, M. B. \& Ludwig, D. S. Obesity and impaired metabolic health in patients with COVID-19. Nat. Rev. Endocrinol. 16, 341-342 (2020).

17. Wang, T. et al. Comorbidities and multi-organ injuries in the treatment of COVID-19. Lancet 395, e52 (2020).

18. Ritchie, H. \& Roser, M. What share of adults are obese? Our World in Data. https://ourworldindata.org/obesity (2017).

19. Ritchie, H. et al. Coronavirus pandemic (COVID-19) Our World In Data. https://ourworldindata.org/ coronavirus (2020)

20. Kass, D. A., Duggal, P. \& Cingolani, O. Obesity could shift severe COVID-19 disease to younger ages. Lancet 395, 1544-1545 (2020)

21. Bhaskaran, K., Dos-Santos-Silva, I., Leon, D. A. Douglas, I. J. \& Smeeth, L. Association of BMI with overall and cause-specific mortality: a populationbased cohort study of 3.6 million adults in the UK. Lancet Diabetes Endocrinol. 6, 944-953 (2018).

22. Stefan, N., Haring, H. U., Hu, F. B. \& Schulze, M. B. Metabolically healthy obesity: epidemiology, mechanisms, and clinical implications. Lancet Diabetes Endocrinol. 1, 152-162 (2013).

23. Cai, Q. et al. Obesity and COVID-19 severity in a designated hospital in Shenzhen, China. Diabetes Care 43, 1392-1398 (2020).

24. Gao, F. et al. Obesity is a risk factor for greater COVID-19 severity. Diabetes Care 43, e72-e74 (2020).

25. Price-Haywood, E. G., Burton, J., Fort, D. \& Seoane, L. Hospitalization and mortality among Black patients and white patients with Covid-19. N. Engl. J. Med. 382, 2534-2543 (2020)

26. Hamer, M., Kivimaki, M., Gale, C. R. \& Batty, G. D. Lifestyle risk factors, inflammatory mechanisms, and COVID-19 hospitalization: a community-based cohort study of 387,109 adults in UK. Brain Behav. Immun. 87, 184-187 (2020)

27. Soares, R. C. M., Mattos, L. R. \& Raposo, L. M. Risk factors for hospitalization and mortality due to
COVID-19 in Espírito Santo State, Brazil. Am. J. Trop. Med. Hyg. 103, 1184-1190 (2020).

28. Kim, L et al. Risk factors for intensive care unit admission and in-hospital mortality among hospitalized adults identified through the U.S. coronavirus disease 2019 (COVID-19)-Associated Hospitalization Surveillance Network (COVID-NET). Clin. Infect. Dis. https://doi.org/10.1093/cid/ciaa1012 (2020).

29. Klang, E. et al. Severe obesity as an independent risk factor for COVID-19 mortality in hospitalized patients younger than 50. Obesity 28, 1595-1599 (2020).

30. Williamson, E. J. et al. Factors associated with COVID-19-related death using OpenSAFELY. Nature. 584, 430-436 (2020).

This is the largest study to investigate independent relationships of comorbidities and mortality in patients with COVID-19.

31. Anderson, M. R. et al. Body mass index and risk for intubation or death in SARS-CoV-2 infection: a retrospective cohort study. Ann. Intern. Med. 173, 782-790 (2020).

32. Bello-Chavolla, O. Y. et al. Predicting mortality due to SARS-CoV-2: a mechanistic score relating obesity and diabetes to COVID-19 outcomes in Mexico. J. Clin. Endocrinol. Metab. 105, dgaa346 (2020).

33. Hippisley-Cox, J. et al. Risk of severe COVID-19 disease with ACE inhibitors and angiotensin receptor blockers: cohort study including 8.3 million people. Heart 106, 1503-1511 (2020).

34. Sattar, N. et al. BMI and future risk for COVID-19 infection and death across sex, age and ethnicity: preliminary findings from UK biobank. Diabetes Metab. Syndr. 14, 1149-1151 (2020).

35. Tartof, S. Y. et al. Obesity and mortality among patients diagnosed with COVID-19: results from an integrated health care organization. Ann. Intern. Med. 173, 773-781 (2020).

36. Cunningham, J. W. et al. Clinical outcomes in young US adults hospitalized with COVID-19. JAMA Intern. Med. https://doi.org/10.1001/jamainternmed.2020.5313 (2020).

This important study shows that young adults with more than one specific comorbid condition (morbid obesity, hypertension and/or diabetes mellitus), faced risks comparable to those observed in middle-aged adults without them

37. Kim, T. et al. Northwell health COVID-19 research consortium. body mass index as a risk factor for clinical outcomes in patients hospitalized with COVID-19 in New York. Obesity https://doi.org/10.1002/oby.23076 (2020).

38. Dennis, J. M. et al. Type 2 diabetes and COVID-19related mortality in the critical care setting: a national 
cohort study in England, March-July 2020. Diabetes Care https://doi.org/10.2337/dc20-1444 (2020).

39. Cariou, B. et al. Phenotypic characteristics and prognosis of inpatients with COVID-19 and diabetes the CORONADO study. Diabetologia 63, 1500-1515 (2020)

40. Neeland, I. J. et al. Visceral and ectopic fat atherosclerosis, and cardiometabolic disease a position statement. Lancet Diabetes Endocrinol. 7 715-725 (2019).

41. Stefan, N. Causes, consequences, and treatment of metabolically unhealthy fat distribution. Lancet Diabetes Endocrinol. 8, 616-627 (2020).

42. Petersen, A. et al. The role of visceral adiposity in the severity of COVID-19: highlights from a unicente cross-sectional pilot study in Germany. Metabolism 110, 154317 (2020)

43. Watanabe, M. et al. Visceral fat shows the strongest association with the need of intensive care in patients with COVID-19. Metabolism 111, 54319 (2020).

44. Yang, Y. et al. Visceral adiposity and high intramuscular fat deposition independently predict critical IIIness in patients with SARS-COV-2. Obesity 28, 2040-2048 (2020)

45. Rao Kondapally Seshasai, S. et al. Diabetes mellitus, fasting glucose, and risk of cause-specific death. N. Engl. J. Med. 364, 829-841 (2011).

46. Stefan, N., Fritsche, A., Schick, F. \& Häring, H. U. Phenotypes of prediabetes and stratification of cardiometabolic risk. Lancet Diabetes Endocrinol. 4 789-798 (2016)

47. Ali, M. K., Bullard, K. M., Saydah, S., Imperatore, G. $\&$ Gregg, E. W. Cardiovascular and renal burdens of prediabetes in the USA: analysis of data from serial cross-sectional surveys, 1988-2014. Lancet Diabetes Endocrinol. 6. 392-403 (2018)

48. Zhang, B., Liu, S., Zhang, L., Dong, Y. \& Zhang, S Admission fasting blood glucose predicts 30-day poor outcome in patients hospitalized for COVID-19 pneumonia. Diabetes Obes. Metab. https://doi.org/ 10.1111/dom.14132 (2020).

49. Targher, G. et al. Patients with diabetes are at higher risk for severe illness from COVID-19. Diabetes Metab. 46, 335-337 (2020)

50. Barron, E. et al. Associations of type 1 and type 2 diabetes with COVID-19-related mortality in England: a whole-population study. Lancet Diabetes Endocrinol. 8, 813-822 (2020)

51. Holman, N. et al. Risk factors for COVID-19-related mortality in people with type 1 and type 2 diabetes in England: a population-based cohort study. Lance Diabetes Endocrinol. 8, 823-833 (2020).

52. Li, H. et al. Newly diagnosed diabetes is associated with a higher risk of mortality than known diabetes in hospitalized patients with COVID-19. Diabetes Obes. Metab. https://doi.org/10.1111/dom.14099 (2020).

53. RECOVERY Collaborative Group. Dexamethasone in hospitalized patients with Covid-19 - Preliminary Report. N. Engl. J. Med. https://doi.org/10.1056/ NEJMoa2021436 (2020)

54. Ponsford, M. J. et al. Cardiometabolic traits, sepsis, and severe COVID-19: a Mendelian randomization investigation Circulation 142, 1791-1793 (2020). Mendelian randomization analyses performed in this study show that a higher genetically proxied BMI was associated with increased risk of severe COVID-19.

55. Ellinghaus, D. et al. Genomewide association study of severe Covid-19 with respiratory failure. N. Engl. J. Med. 383, 1522-1534 (2020)

56. Lan, J. et al. Structure of the SARS-CoV-2 spike receptor-binding domain bound to the ACE2 receptor. Nature 581, 215-220 (2020).

57. Shang, J. et al. Structural basis of receptor recognition by SARS-CoV-2. Nature. 581, 221-224 (2020).

58. Walls, A. C. et al. Structure, function, and antigenicity of the SARS-CoV-2 spike glycoprotein. Cell 181 281-292 (2020)

59. Hoffmann, M. et al. SARS-CoV-2 cell entry depends on ACE2 and TMPRSS2 and is blocked by a clinically proven protease inhibitor. Cell 181, 271-280 (2020).

60. Sungnak, W. et al. SARS-CoV-2 entry factors are highly expressed in nasal epithelial cells together with innate immune genes. Nat. Med. 26, 681-687 (2020).

61. Puelles, V. G. et al. Multiorgan and renal tropism of SARS-CoV-2. N. Engl. J. Med. 383, 590-592 (2020).

62. Su, H. et al. Renal histopathological analysis of 26 postmortem findings of patients with COVID-19 in China. Kidney Int. 98, 219-227 (2020).

63. Tavazzi, G. et al. Myocardial localization of coronavirus in COVID-19 cardiogenic shock. Eur. J. Heart Fail. 22, 911-915 (2020).
64. Xiao, F. et al. Evidence for gastrointestinal infection of SARS-CoV-2. Gastroenterology 158, 1831-1833 (2020).

65. Gupta, A. et al. Extrapulmonary manifestations of COVID-19. Nat. Med. 26, 1017-1032 (2020). This review article very well summarizes the mechanisms of interaction of SARS-CoV-2 with host cells and extrapulmonary manifestation of COVID-19.

66. Ayres, J. S. A metabolic handbook for the COVID-19 pandemic. Nat. Metab. 2, 572-585 (2020).

67. Blokhin, I. O. \& Lentz, S. R. Mechanisms of thrombosis in obesity. Curr. Opin. Hematol. 20, 437-444 (2013).

68. Shimomura, I. et al. Enhanced expression of PAI-1 in visceral fat: possible contributor to vascular disease in obesity. Nat. Med. 2, 800-803 (1996)

69. Ouchi, N., Parker, J. L., Lugus, J. J. \& Walsh, K. Adipokines in inflammation and metabolic disease. Nat. Rev. Immunol. 11, 85-97 (2011).

70. Ackermann, M. et al. Pulmonary vascular endothelialitis, thrombosis, and angiogenesis in Covid-19. N. Engl. J. Med. 383, 120-128 (2020).

This article provides important information about how SARS-CoV-2 enters endothelial cells via ACE2 and induces endotheliitis and potentially thrombosis.

71. Varga, Z. et al. Endothelial cell infection and endotheliitis in COVID-19. Lancet 395, 1417-1418 (2020).

72. Mehta, P. et al. HLH across speciality collaboration, UK COVID-19: consider cytokine storm syndromes and immunosuppression. Lancet 395, 1033-1034 (2020)

73. Lala, A. et al. Prevalence and impact of myocardial injury in patients hospitalized with COVID-19 infection. J. Am. Coll. Cardiol. 76, 533-546 (2020).

74. Bonow, R. O. Fonarow, G. C. O'Gara, P. T \& Yancy, C. W. Association of coronavirus disease 2019 (COVID-19) with myocardial injury and mortality. JAMA Cardiol. 5, 751-753 (2020).

75. Hendren, N. S., Drazner, M. H., Bozkurt, B. \& Cooper, L. T. Jr. Description and proposed management of the acute COVID-19 cardiovascular syndrome. Circulation 141, 1903-1914 (2020).

76. Lim, G. B. Myocardial injury in patients with COVID-19. Nat. Rev. Cardiol. 17, 454 (2020)

77. Uriel, N., Sayer, G. \& Clerkin, K. J. Myocardial injury in COVID-19 patients: the beginning or the end? J. Am. Coll. Cardiol. 76, 547-549 (2020).

78. Nishiga, M., Wang, D. W., Han, Y., Lewis, D. B. \& Wu, J. C. COVID-19 and cardiovascular disease: from basic mechanisms to clinical perspectives. Nat. Rev. Cardiol. 17, 543-558 (2020).

79. Webster, A. C., Nagler, E. V., Morton, R. L. \& Masson, P. Chronic kidney disease. Lancet 389, 1238-1252 (2017).

80. Artunc, F. et al. The impact of insulin resistance on the kidney and vasculature. Nat. Rev. Nephrol. 12, 721-737 (2016)

81. Naicker, S. et al. The novel coronavirus 2019 epidemic and kidneys. Kidney Int. 97, 824-828 (2020).

82. Cheng, Y. et al. Kidney disease is associated with in-hospital death of patients with COVID-19. Kidney Int 97, 829-838 (2020)

83. Martinez-Rojas, M. A., Vega-Vega, O. \& Bobadilla, N. A Is the kidney a target of SARS-CoV-2? Am. J. Physiol. Ren. Physiol. 318, F1454-F1462 (2020).

84. Stefan, N., Häring, H. U. \& Cusi, K. Non-alcoholic fatty liver disease: causes, diagnosis, cardiometabolic consequences, and treatment strategies. Lancet Diabetes Endocrinol. 7, 313-324 (2019).

85. Younossi, Z. et al. Global burden of NAFLD and NASH trends, predictions, risk factors and prevention. Nat Rev. Gastroenterol. Hepatol. 15, 11-20 (2018).

86. Eslam, M. et al. A new definition for metabolic dysfunction-associated fatty liver disease: An international expert consensus statement. J. Hepatol. 73, 202-209 (2020).

87. Zhou, Y. J. et al. Metabolic-associated fatty liver diseas is associated with severity of COVID-19. Liver Int. $\mathbf{4 0}$ 2160-2163 (2020)

88. Targher, G. et al. Risk of severe illness from COVID-19 in patients with metabolic dysfunction-associated fatty liver disease and increased fibrosis scores. Gut. 69 1545-1547 (2020).

89. Bertolini, A. et al. Abnormal liver function tests in COVID-19 patients: relevance and potential pathogenesis. Hepatology. 72, 1864-1872 (2020).

90. Hikmet, F. et al. The protein expression profile of ACE2 in human tissues. Mol. Syst. Biol. 16, e9610 (2020).

91. De Smet, V., Verhulst, S. \& van Grunsven, L. A. Single cell RNA sequencing analysis did not predict hepatocyte infection by SARS-CoV-2. J. Hepatol. 73, 993-995 (2020).

92. Hundt, M. A., Deng, Y., Ciarleglio, M. M Nathanson, M. H. \& Lim, J. K. Abnormal liver tests in
COVID-19: a retrospective observational cohort study of 1827 patients in a major U.S. hospital network. Hepatology https://doi.org/10.1002/hep.31487 (2020)

93. Soldo, J. et al. Increased hepatic ACE2 expression in NAFL and diabetes - a risk for COVID-19 patients? Diabetes Care 43, e134-e136 (2020).

94. Li, H. et al. SARS-CoV-2 and viral sepsis: observations and hypotheses. Lancet. 395, 1517-1520 (2020).

95. Nunes Duarte-Neto, A. et al. Pulmonary and systemic involvement of COVID-19 assessed by ultrasoundguided minimally invasive autopsy. Histopathology 77 186-197 (2020).

96. Sonzogni, A. et al. Liver histopathology in severe COVID 19 respiratory failure is suggestive of vascular alterations. Liver Int. 40, 2110-2116 (2020).

97. Lamers, M. M. et al. SARS-CoV-2 productively infects human gut enterocytes. Science. 369, 50-54 (2020). This important study reports that SARS-CoV and SARS-CoV-2 readily infect enterocytes.

98. Gu, J., Han, B. \& Wang, J. COVID-19: gastrointestinal manifestations and potential fecal-oral transmission. Gastroenterology 158, 1518-1519 (2020).

99. Sonnenburg, J. L. \& Bäckhed, F. Diet-microbiota interactions as moderators of human metabolism Nature 535, 56-64 (2016)

100. Tilg, H., Zmora, N., Adolph, T. E. \& Elinav, E. The intestinal microbiota fuelling metabolic inflammation. Nat. Rev. Immunol. 20, 40-54 (2020).

101. Marra, F. \& Svegliati-Baroni, G. Lipotoxicity and the gut-liver axis in NASH pathogenesis. J. Hepatol. 68 280-295 (2018)

102. Luck, H. et al. Regulation of obesity-related insulin resistance with gut anti- inflammatory agents. Cell Metab. 21, 527-542 (2015)

103. Xu, Z. et al. Pathological findings of COVID-19 associated with acute respiratory distress syndrome. Lancet Respir. Med. 8, 420-422 (2020). In this study, an increase in IL-17-producing $T_{H} 17$ cells and a high cytotoxicity of $C D 8^{+} T$ cells is being observed in the peripheral blood of patients with COVID-19, which is thought to have an important role in the cytokine storm of COVID-19.

104. Wu, D. \& Yang, X. O. $T_{H} 17$ responses in cytokine storm of COVID-19: an emerging target of JAK2 inhibitor fedratinib. J. Microbiol. Immunol. Infect. 53, 368-370 (2020).

105. De Biasi, S. et al. Marked T cell activation, senescence, exhaustion and skewing towards $\mathrm{T}_{\mathrm{H}} 17$ in patients with COVID-19 pneumonia. Nat. Commun. 11, 3434 (2020).

106. Wang, F. et al. The laboratory tests and host immunity of COVID-19 patients with different severity of illness. JCI Insight 5, e137799 (2020).

107. Liu, F. et al. ACE2 expression in pancreas may cause pancreatic damage after SARS-CoV-2 infection. Clin. Gastroenterol. Hepatol. 18, 2128-2130 (2020).

108. Yang, J. K., Lin, S. S., Ji, X. J. \& Guo, L. M. Binding of SARS coronavirus to its receptor damages islets and causes acute diabetes. Acta Diabetol. 47, 193-199 (2010)

109. Reddy, P. K., Kuchay, M. S., Mehta, Y. \& Mishra, S. K. Diabetic ketoacidosis precipitated by COVID-19: a report of two cases and review of literature Diabetes Metab. Syndr. 14, 1459-1462 (2020).

110. Li, J. et al. COVID-19 infection may cause ketosis and ketoacidosis. Diabetes Obes. Metab. https://doi.org/ 10.1111/dom. 14057 (2020)

111. Armeni, E. et al. Protracted ketonaemia in hyperglycaemic emergencies in COVID-19: a retrospective case series. Lancet Diabetes Endocrinol. 8, 660-663 (2020)

112. Bornstein, S. R. et al. Practical recommendations for the management of diabetes in patients with COVID-19. Lancet Diabetes Endocrinol. 8, 546-550 (2020).

113. Apicella, M. et al. COVID-19 in people with diabetes: understanding the reasons for worse outcomes. Lancet Diabetes Endocrinol. 8, 782-792 (2020).

114. Rubino, F. et al. New-onset diabetes in Covid-19. N. Engl. J. Med. 383, 789-790 (2020)

115. Moldofsky, H. \& Patcai, J. Chronic widespread musculoskeletal pain, fatigue, depression and disordered sleep in chronic post-SARS syndrome; a case-controlled study. BMC Neurol 11, 37 (2011).

116. Lee, S. H. et al. Depression as a mediator of chronic fatigue and post-traumatic stress symptoms in middle east respiratory syndrome survivors. Psychiatry Investig. 16, 59-64 (2019).

117. Ahmed, $\mathrm{H}$. et al. Long-term clinical outcomes in survivors of severe acute respiratory syndrome and Middle East respiratory syndrome coronavirus outbreaks after hospitalisation or ICU admission. J. Rehabil. Med 52, jrm00063 (2020). 
118. Prescott, H. C. \& Girard, T. D. Recovery from severe COVID-19: leveraging the lessons of survival from sepsis. JAMA 324, 739-740 (2020).

119. Carfi, A., Bernabei, R., Landi, F. \& Gemelli Against COVID-19 Post-Acute Care Study Group. Persistent symptoms in patients after acute COVID-19. JAMA 324, 603-605 (2020).

120. Olsen, R. H., Krogh-Madsen, R., Thomsen, C. Booth, F. W. \& Pedersen, B. K. Metabolic responses to reduced daily steps in healthy nonexercising men JAMA 299, 1261-1263 (2008).

121. Pan, A. et al. Bidirectional association between depression and obesity in middle-aged and older women. Int. J. Obes. 36, 595-602 (2012).

122. Almandoz, J. P. et al. Impact of COVID-19 stay-athome orders on weight-related behaviours among patients with obesity. Clin. Obes. 10, e12386 (2020).

123. Fitbit. The impact of coronavirus on global activity. https://blog.fitbit.com/covid-19-global-activity/ (2020).

124. Muniz-Pardos, B. et al. Collateral health issues derived from the Covid-19 pandemic. Sports Med. Open 6, 35 (2020).

125. Adams, E. L., Caccavale, L. J., Smith, D. \& Bean, M. K. Food insecurity, the home food environment, and parent feeding practices in the era of COVID-19. Obesity 28, 2056-2063 (2020)

126. Leddy, A. M., Weiser, S. D., Palar, K. \& Seligman, H. A conceptual model for understanding the rapid COVID-19-related increase in food insecurity and its impact on health and healthcare. Am. J. Clin. Nutr. 112, 1162-1169 (2020).

127. Rubino, F. et al. Bariatric and metabolic surgery during and after the COVID-19 pandemic: DSS recommendations for management of surgical candidates and postoperative patients and prioritisation of access to surgery. Lancet Diabetes Endocrinol. 8, 640-648 (2020).

128. Marinari, G. M. et al. Bariatric and metabolic surgery during COVID-19 outbreak phase 2 in Italy: why, when and how to restart. Surg. Obes. Relat. Dis. 16 , 1614-1618 (2020)

129. Hussain, A., Mahawar, K. \& El-Hasani, S. The impact of COVID-19 pandemic on obesity and bariatric surgery. Obes. Surg. 30, 3222-3223 (2020)

130. Clemmensen, C., Petersen, M. B. \& Sørensen, T. I. A. Will the COVID-19 pandemic worsen the obesity epidemic? Nat. Rev. Endocrinol. 16, 469-470 (2020).

131. Puntmann, V. O. et al. Outcomes of cardiovascular magnetic resonance imaging in patients recently recovered from coronavirus disease 2019 (COVID-19). JAMA Cardiol. 5, 1265-1273 (2020).

Using cardiovascular MRI, this study shows ongoin myocardial inflammation in many of the studied patients who recently recovered from COVID-19 illness.

132. Ghosal, S. et al. Increase in the risk of type 2 diabetes during lockdown for the COVID19 pandemic in India: a cohort analysis. Diabetes Metab. Syndr. 14, 949-952 (2020).

133. Ghosal, S., Sinha, B., Majumder, M. \& Misra, A Estimation of effects of nationwide lockdown for containing coronavirus infection on worsening of glycosylated haemoglobin and increase in diabetesrelated complications: a simulation model using multivariate regression analysis. Diabetes Metab. Syndr. 14, 319-323 (2020).

134. Rosenbaum, L. The untold toll - the pandemic's effects on patients without Covid-19. N. Engl. J. Med. 382, 2368-2371 (2020)

135. Baum, A. \& Schwartz, M. D. Admissions to veterans affairs hospitals for emergency conditions during the COVID-19 pandemic. JAMA 324, 96-99 (2020).

136. Kamrath, C. et al. Ketoacidosis in children and adolescents with newly diagnosed type 1 diabetes during the COVID-19 pandemic in Germany. JAMA 324, 801-804 (2020).

137. Rubin, E. J., Baden, L. R., Epstein, A. \& Morrissey, S. Audio interview: the impact of Covid-19 on patients with other diseases, with Arnold Epstein. N. Engl. J. Med. 383, e62 (2020).

138. Maringe, C. et al. The impact of the COVID-19 pandemic on cancer deaths due to delays in diagnosis in England, UK: a national, population-based, modelling study. Lancet Oncol. 21, 1023-1034 (2020).

139. Bromage, D. I. et al. The impact of COVID-19 on heart failure hospitalization and management: report from a Heart Failure Unit in London during the peak of the pandemic. Eur. J. Heart Fail. 22, 978-984 (2020).

140. Metzler, B., Siostrzonek, P., Binder, R. K., Bauer, A. \& Reinstadler, S. J. Decline of acute coronary syndrome admissions in Austria since the outbreak of COVID-19. the pandemic response causes cardiac collateral damage. Eur. Heart J. 41, 1852-1853 (2020).

141. Vetrovsky, T. et al. The detrimental effect of COVID-19 nationwide quarantine on accelerometer-assessed physical activity of heart failure patients. ESC Heart Fail. 7, 2093-2097 (2020)

142. Goldman, J. D. et al. Remdesivir for 5 or 10 days in patients with severe Covid-19. N. Engl. J. Med. 383 1827-1837 (2020).

143. Lane, H. C. \& Fauci, A. S. Research in the context of a pandemic. N. Engl. J. Med. https://doi.org/10.1056/ NEJMe2024638 (2020).

144. Hazeldine, J. \& Lord, J. M. Immunesenescence: a predisposing risk factor for the development of COVID-19? Front. Immunol. 11, 573662 (2020)

145. Kumar, V. How could we forget immunometabolism in SARS-CoV2 infection or COVID-19? Int. Rev. Immunol. https://doi.org/10.1080/08830185.2020.1840567 (2020).

146. Popkin, B. M. et al. Individuals with obesity and COVID-19: a global perspective on the epidemiology and biological relationships. Obes. Rev. 21, e13128 (2020).

147. Ledford, H. How obesity could create problems for a COVID vaccine. Nature 586, 488-489 (2020). This article discusses that COVID-19 vaccines migh not be as effective in people with obesity as in lean individuals.

148. De La Fuente, M. \& De Castro, N. M. Obesity as a model of premature immunosenescence. Curr. Immunol. Rev. https://doi.org/10.2174/157339512798991290 (2020).

149. Lau, E. Y. M. et al. Type 2 diabetes is associated with the accumulation of senescent T cells. Clin. Exp. Immunol. 197, 205-213 (2019).

150. Frasca, D. et al. Obesity decreases B cell responses in young and elderly individuals. Obesity 24, 615-625 (2016).

151. Sheridan, P. A. et al. Obesity is associated with impaired immune response to influenza vaccination in humans. Int. J. Obes. 36, 1072-1077 (2012).

152. Paich, H. A. et al. Overweight and obese adult humans have a defective cellular immune response to pandemic H1N1 influenza A virus. Obesity 21, 2377-2386 (2013).

153. Neidich, S. D. et al. Increased risk of influenza among vaccinated adults who are obese. Int. J. Obes. 41, 1324-1330 (2017).

154. Egawa, Y. et al. Immunogenicity of influenza A(H1N1) pdm09 vaccine in patients with diabetes mellitus: with special reference to age, body mass index, and $\mathrm{HbA} 1 \mathrm{c}$. Hum. Vaccin. Immunother 10, 1187-1194 (2014).

155. Eckel, R. H. et al. 2013 AHA/ACC guideline on lifestyle management to reduce cardiovascular risk: a report of the American College of Cardiology/American Heart Association Task Force on Practice Guidelines. Circulation 129, S76-S99 (2014).

156. American College of Cardiology/American Heart Association Task Force on Practice Guidelines, Obesity Expert Panel, 2013. Executive summary: guidelines (2013) for the management of overweight and obesity in adults: a report of the American College of Cardiology/American Heart Association Task Force on Practice Guidelines and the Obesity Society published by the Obesity Society and American College of Cardiology/American Heart Association Task Force on Practice Guidelines. Based on a systematic review from the The Obesity Expert Panel, 2013. Obesity 22, S5-S39 (2014).

157. Stefan, N., Häring, H. U. \& Schulze, M. B. Metabolically healthy obesity: the low-hanging fruit in obesity treatment? Lancet Diabetes Endocrinol. 6, 249-258 (2018). This study highlights the importance of achieving metabolic health in different stages of adiposity.

158. Estruch, R. et al. Primary prevention of cardiovascular disease with a mediterranean diet supplemented with extra-virgin olive oil or nuts. N. Engl. J. Med. 378, e34 (2018).

159. Estruch, R. et al. Effect of a high-fat Mediterranean diet on bodyweight and waist circumference: a prespecified secondary outcomes analysis of the PREDIMED randomised controlled trial. Lancet Diabetes Endocrinol. 7, e6-e17 (2019).

160. Puchalska, P. \& Crawford, P. A. Multi-dimensional roles of ketone bodies in fuel metabolism, signaling, and therapeutics. Cell Metab. 25, 262-284 (2017).

161. Augustin, K. et al. Mechanisms of action for the medium-chain triglyceride ketogenic diet in neurological and metabolic disorders. Lancet Neurol. 17, 84-93 (2018)
162. Ang, Q. Y. et al. Ketogenic diets alter the gut microbiome resulting in decreased intestinal Th17 cells. Cell 181, 1263-1275 (2020) This study finds that the ketogenic diet decreased the levels of intestinal pro-inflammatory $T_{H} 17$ cells in mice, the cell type that is thought to largely contribute to the proinflammatory response observed in COVID-19.

163. Fedorovich, S. V., Voronina, P. P. \& Waseem, T. V. Ketogenic diet versus ketoacidosis: what determines the influence of ketone bodies on neurons? Neural Regen. Res. 13, 2060-2063 (2018).

164. US Preventive Services Task Force Behavioral counseling interventions to promote a healthy diet and physical activity for cardiovascular disease prevention in adults with cardiovascular risk factors: US preventive services task force recommendation statement. JAMA 324, 2069-2075 (2020).

165. Heymsfield, S. B. \& Wadden, T. A. Mechanisms, pathophysiology, and management of obesity. N. Engl. J. Med. 376, 254-266 (2017)

166. Yanovski, S. Z. \& Yanovski, J. A. Long-term drug treatment for obesity: a systematic and clinical review. JAMA 311, 74-86 (2014)

167. Blüher, M. Metabolically healthy obesity. Endocr. Rev. 41, 405-420 (2020)

168. Ghosh-Swaby, O. R. et al. Glucose-lowering drugs or strategies, atherosclerotic cardiovascular events, and heart failure in people with or at risk of type 2 diabetes: an updated systematic review and metaanalysis of randomised cardiovascular outcome trials. Lancet Diabetes Endocrinol 8, 418-435 (2020).

169. Blüher, M. Obesity: global epidemiology and pathogenesis. Nat. Rev. Endocrinol. 15, 288-298 (2019).

170. Hawkes, C. et al. Smart food policies for obesity prevention. Lancet 385, 2410-2421 (2015).

171. Public Health England. Press Release: Major new campaign encourages millions to lose weight and cut COVID-19 risk. GOV.UK https://www.gov.uk/ government/news/major-new-campaign-encouragesmillions-to-lose-weight-and-cut-covid-19-risk (2020).

172. Nugent, C. 'I Was Too Fat.' Prime Minister Boris Johnson says Brits must lose weight to fight coronavirus. TIME https://time.com/5872175/ boris-johnson-weight-loss-coronavirus/ (2020)

173. Gostin, L. O., Hodge, J. G. \& Levin, D. E. Legal interventions to address US reductions in life expectancy. JAMA 324, 1037-1038 (2020).

174. Mahase, E. Covid-19: England's obesity strategy will fail without tackling social factors, warn doctors. Br. Med. J. 370, m2994 (2020).

175. [No author listed]. UK policy targeting obesity during a pandemic - the right approach? Nat. Rev. Endocrinol. 16, 609 (2020).

176. Rodgers, G. P. \& Collins, F. S. Precision nutrition-the answer to "What to Eat to Stay Healthy". JAMA 324 $735-736$

177. US Department of Health \& Human Services; National Institutes of Health. 2020-2030 Strategic Plan for NIH Nutrition Research. https://www.niddk.nih.gov/ about-niddk/strategic-plans-reports/strategic-plan-nihnutrition-research (2020).

\section{Acknowledgements}

The authors acknowledge the support of funding from the German Research Foundation, the German Federal Ministry of Education and Research to the German Centre of Diabetes Research and the European Innovative Medicines Initiative SOPHIA.

\section{Author contributions}

N.S. and M.B.S. researched data for the article and wrote the article. All the authors made substantial contributions to the discussion of content and carried out review/editing of the manuscript before submission.

\section{Competing interests}

The authors declare no competing interests.

\section{Peer review information}

Nature Reviews Endocrinology thanks J. Wilding, M.-H. Zheng and the other, anonymous, reviewer(s) for their contribution to the peer review of this work.

\section{Publisher's note}

Springer Nature remains neutral with regard to jurisdictional claims in published maps and institutional affiliations.

(C) Springer Nature Limited 2021 